\title{
FIDELIDAD, LIBRE ADAPTACIÓN, RECREACIÓN. ITINERARIOS DEL TEATRO ITALIANO EN LA ESPAÑA DEL SIGLO XVIII (1735-1808): NOTAS SOBRE RECEPCIÓN Y TRADUCCIÓN*
}

\section{Faithful Translation, Free Adaptation, Recreation. Itineraries of the Italian Drama in 18th Century Spain (1735-1808): Notes about Reception and Translation}

\author{
Franco QUINZIANO \\ IEMYRhd-Universidad de Salamanca \\ GREC-Universidad de Oviedo \\ francoquinzi@msn.com
}

Fecha de recepción: 12/03/2021

Fecha de aceptación definitiva: 14/07/2021

RESUMEN: El siglo XVIII fue testigo de la significativa presencia y recepción que exhibieron dos autores claves en el campo teatral, Metastasio y Goldoni, cuyas obras gozaron de gran popularidad en los escenarios españoles. En torno a estos dos dramaturgos se concitó una intensa labor traductora que fue configurando un notable repertorio de piezas -traducidas, adaptadas y arregladas- del que se nutrieron el drama musical y el teatro cómico en España. Significativa fue la aportación del caudal de textos teatrales italianos para la formación de un renovado repertorio en las carteleras españolas, amoldados a los gustos del público y a múltiples subgéneros dramáticos. En el estudio se abordan el horizonte de la recepción del drama italiano y algunos itinerarios por los que transitaron las versiones españolas,

* El presente estudio se inscribe en las líneas del proyecto de investigación del Ministerio de Ciencia e Innovación: Portal digital de Historia de la Traducción en España, PGC2018-095447-B-I00 (MCIU/AEI/FEDER, UE). 
procedentes en especial de ambos autores, a partir de mediados de los años 30 del siglo, cuando el drama metastasiano ingresa en la península. Una parcela relevante de estas versiones en español evidencia modalidades y trayectos complejos y sinuosos en su proceso de adaptación, al tiempo que exhiben diversos niveles de interconexión y de interdependencia, directa e indirecta, tanto entre sí como respecto al texto original italiano del que han bebido.

Palabras clave: teatro italiano; recepción y traducción en España; siglo XVIII; Metastasio; Goldoni.

ABSTRACT: The eighteenth century witnessed the significant presence and reception exhibited by two essential Italian authors in the theatrical field, Metastasio and Goldoni, whose works enjoyed great popularity on the Spanish stages. An intense translating work was developed around these two dramatists. This valuable work was configuring a remarkable repertoire of pieces -translated, adapted and arranged-for the musical drama and comic theater in Spain. The horizon of the reception of the Italian drama and some itineraries through which the Spanish versions -especially from both authors- traveled are explored in this study, in its adaptation phase to Spanish theater from the mid-30s of the $18^{\text {th }}$ Century. An important part of these versions and adaptations in Spanish show complex and sinuous modalities and paths in their adaptation process. Likewise, these pieces exhibit different levels of interconnection and interdependence, direct and indirect, among themselves and also with respect to the original Italian text from which they come.

Key words: Italian theatre; reception and translation in Spain; $18^{\text {th }}$ Century; Metastasio; Goldoni.

\section{INTRODUCCIÓN}

El siglo XVIII, como es sabido, es un siglo de efervescencia de la actividad traductora. En la perspectiva utilitaria y cosmopolita que caracteriza el Siglo de las Luces, el traductor se propuso difundir obras extranjeras en la lengua de su país con el propósito de contribuir al progreso de la nación. Los escritores y hombres de saber españoles del XVIII, imbuidos de una amplia cultura enciclopedista y europeísta, percibieron la importancia de la actividad traductora para la promoción y difusión del saber entre las diversas naciones. En palabras de Clavijo y Fajardo, se trataba de "trasladar al idioma, para beneficio de su nación, lo mejor que hay escrito en otras lenguas» ${ }^{1}$.

1. García Garrosa, M. ${ }^{\text {a }}$ Jesús y Lafarga, Francisco. "La historia de la traducción en España en el siglo XVIII". En SABIo PINILLA, José A. (ed.). La traducción en la época ilustrada (panorámicas de la traducción en el siglo XVIII). Granada: Comares, 2009, p. 40. 
Algunos propiciaron la literalidad y el ajuste total al texto original, como el helenista Ranz Romanillos; otros la fidelidad al texto - no confundirla con literalidad- como garantía de una buena y fiable traducción (José de Covarrubias o Francisco P. de Berguizas, entre ellos); mientras que hubo no pocos que, por el contrario, fueron partidarios de exhibir una mayor libertad a la hora de encarar la labor traductora (Trigueros y Ramón de la Cruz, entre otros) ${ }^{2}$, convirtiendo en lábiles los ámbitos de la traducción y la adaptación ${ }^{3}$. Si algunos percibieron, pues, en la actividad traductora un inestimable canal de enriquecimiento cultural, otros la concibieron en cambio como vehículo de degradación lingüística; unos aprobaron la penetración de vocablos procedentes de otras lenguas, en especial la francesa, como elemento que enriquecía el patrimonio léxico, mientras que no fueron pocos los que se opusieron enérgicamente, concibiendo la traducción, con la consiguiente invasión de vocablos extranjeros, como factor que conllevaba el empobrecimiento y la deturpación del idioma ${ }^{4}$.

En dicha perspectiva la traducción, en especial en la segunda mitad de la centuria, fue sometida a una intensa reflexión y a un acalorado debate, cuyos contenidos se hallan diseminados en los prólogos y la prensa cultural del periodo y en el que es posible percibir posiciones en contienda y teorías lingüísticas dialogando dialécticamente entre sî́. La aproximación a la labor traductora, las características y propiedades que debía poseer el traductor, así como las dificultades

2. «Cuando traduzca, lo haré libremente, y jamás al pie de la letra; alteraré, mudaré, quitaré y añadiré lo que me pareciere, a propósito para mejorar el original», Cándido Trigueros, Mis pasatiempos (1804), cit. en Ruiz CaSANova, José. Aproximación a una bistoria de la traducción en España. Madrid: Cátedra, 2000, p. 357, nota 44.

3. Por adaptación, siguiendo el criterio de Pavis, se entiende "todas las maniobras textuales imaginables [que] están permitidas: rupturas, reorganización del relato, reducción del número de personajes, concentración dramática, en ciertos momentos intensos [...], incorporación de textos exteriores, montaje y collage de elementos externos, modificación de la conclusión, etc.», PAvIs, Patrice. Diccionario del teatro. Dramaturgia, estética, semiología. Barcelona: Paidós, 1983, p. 23.

4. Uno de los aspectos que mayormente preocupó a los lingüistas y literatos fue la penetración e influencia de las lenguas extranjeras en el idioma español, especialmente el francés, concebidas por muchos como fuente de corrupción del idioma. No es este el lugar para ahondar sobre dicha cuestión; solo apuntar que, del conjunto de posiciones y teorías, la que revistió mayor importancia fue sin duda la que formuló Capmany, quien, en su Arte de traducir al francés el castellano (1776), reflexionó agudamente sobre la labor traductora, al enunciar algunos principios modernos, inscribiendo "la actividad traductora en el proceso de la cultura contemporánea [...], a partir de resultados empíricos y agudas observaciones lingüísticas y literarias», Ruiz CaSAnOva, José. Op. cit., 2000, p. 323.

5. Un panorama sobre las diversas posiciones y teorías lingüísticas asociadas al arte de la traducción en el XVIII español puede encontrarse en RuIZ CASANOVA, José. Op. cit., 2000, pp. 318-344 y en LAFARGa, Francisco. "El siglo XVIII, de la Ilustración al Romanticismo». En LAFARGA, Francisco y Pegenaute, Luis (eds.). Historia de la traducción en España. Salamanca: Ambos Mundos, 2004, pp. 213241. Las posiciones acerca de la labor traductora y de los ejes discursivos sobre los que giró el debate en la Italia del periodo, en líneas generales, discurren por cauces similares, pudiéndose reconocer esencialmente dos actitudes: los defensores de la fedeltà en oposición a los que se erigen en valedores de la bellezza como principal criterio a seguir, con una variedad de matices entre ambas posiciones. 
que este debía sortear a la hora de volcar el texto original, fueron algunos de los temas que suscitaron el interés de los escritores, preceptistas y eruditos del periodo. Tomás de Iriarte ${ }^{6}$, destacado escritor y uno de los traductores más acreditados del periodo, al afrontar las dificultades que presentaba la labor traductora en los años finales del siglo, resaltaba la diferencia entre aquellos que acometían su labor preparados y con conciencia lingüística de quienes, sin formación, habían hecho de la traducción un oficio pane lucrando; distinguía, pues, entre buenos y malos traductores, adjudicando a estos últimos, debido a su poca pericia, la mayor responsabilidad en el empobrecimiento y corrupción de la lengua.

La ampliación de los vínculos culturales, la mayor facilidad en el acceso a las lenguas extranjeras, junto a las ansias de saber y conocimiento de la época, suscitaron un mayor interés -y empeño- por volcar los textos extranjeros al español. La centuria fue testigo de la significativa presencia y recepción que exhibieron dos autores claves en campo teatral, Pietro Metastasio (nombre helenizado de Pietro Trapassi) y Carlo Goldoni, cuyas obras gozaron de gran popularidad en los escenarios españoles a partir de finales de los años 30 del siglo hasta los albores del XIX. En torno a estos dos dramaturgos, como se ha observado, «entre los autores del XVIII, los más traducidos [...], según los datos más fidedignos»”, se concitó una intensa labor traductora que fue configurando un notable repertorio de piezas -traducidas, adaptadas y arregladas- del que se nutrieron el drama musical y el teatro cómico y que corroboran la notable recepción que alcanzaron ambos autores en la España del periodo. A estos dos acreditados nombres habría que añadir el de Vittorio Alfieri, aunque el tragediógrafo de Asti ocupa muy parcialmente el periodo aquí tratado, puesto que su presencia y recepción se refieren a los últimos años del XVIII y primeros decenios del XIX, coincidiendo con el teatro de implicaciones políticas de la guerra de la Independencia y el Trienio Liberal. Hay que esperar a principios del siglo XIX para registrar la primera traducción española, Lucrecia Pazzi (La congiura dei Pazzi), cuya versión adaptada por Rodríguez Ledesma ve la luz en 1805. Ese mismo año el poeta Sánchez Barbero adapta el Saúl alfieriano y ya a partir de entonces se suceden los títulos del dramaturgo italiano y sus representaciones, cuyo interés fue creciendo al calor de la resistencia contra la invasión napoleónica y los anhelos de libertad contra el Antiguo Régimen.

El auge de las traducciones implicó una ampliación de los horizontes culturales en ambos sentidos y una contribución significativa al proceso de circulación e intercambio de ideas, al tiempo que los traductores acabaron erigiéndose en privilegiados intermediarios entre ambas culturas en contacto. La literatura italiana y su idioma, no cabe duda, concitaron a lo largo de la centuria el interés de literatos y hombres de saber de España; ello se explica en gran parte tanto por la persistencia

6. IRIARTE, Tomás. Los literatos en Cuaresma. E. Martínez Mata y J. Pérez-Magallón (eds.). Madrid: Biblioteca Nueva, 2005, pp. 200-202.

7. Lafarga, Francisco (ed.). Op. cit., 1999, p. 19. 
de la cultura y lengua de Dante como vehículo privilegiado del patrimonio clásico y humanista, como así también por la reavivación de los lazos culturales y literarios que la España de los Borbones entabló con la Italia del Settecento, de modo decisivo en la segunda mitad de la centuria.

Junto con el francés, el idioma italiano era una lengua bien conocida por los hombres de cultura del periodo, constituyendo la italiana la segunda lengua mayormente traducida, después del francés, por delante del latín ${ }^{8}$ : escritores de la talla de Luzán, Cadalso, Iriarte, Ramón de la Cruz y Jovellanos, entre otros, conocían perfectamente el idioma de Dante y varios de ellos vertieron piezas italianas, adecuándolas al gusto español. Diversas fueron las alternativas que se les presentaban a quienes acometían la labor traductora del italiano: para el caso de obras teatrales una de las disyuntivas fue si respetar el verso de la pieza original (por lo general endecasílabos sueltos) o adecuar el texto al octosílabo hispánico o bien trasladar incluso los versos originales a la prosa, más adecuada esta en opinión de los neoclásicos para representar con verosimilitud situaciones de vida cotidiana y de conversación familiar.

Las afinidades entre las dos lenguas sorelle hizo que no pocos autores, sin un cabal conocimiento de la lengua italiana, se lanzasen a traducir los textos, exhibiendo errores y calcos lingüísticos que en no pocas ocasiones arrojaron resultados poco satisfactorios, sin olvidar, por otro lado -aunque no fueron los casos más significativos-, que en varias ocasiones estas traducciones no se emprendían desde los originales italianos, sino que se acometían, sobre todo en el campo teatral, desde el francés como lengua intermediaria o de interferencia?

El influjo de la lengua italiana a través de los textos constituye un aspecto de ningún modo secundario al abordar estos textos: en dicha perspectiva, $\operatorname{Arce}^{10}$ enfatiza el problema del alcance lingüístico que representaron, por ejemplo, las traducciones de Metastasio, al apuntar que no pocos vocablos o expresiones procedentes de sus libretos, muchos de ellos con claras intenciones caricaturescas, acabaron ingresando en el léxico español para asentarse definitivamente en nuestro

8. Según García-HurTado, de los algo más de 2100 títulos traducidos al español y presentes en la Bibliografía de autores de Aguilar Piñal referidos al periodo 1750-1808, los italianos representaron el 19 \% del total, "La traducción en España, 1750-1808: cuantificación y lenguas en contacto». En LAFARGA, Francisco (ed.). La traducción en España (1750-1830). Op. cit., 1999, pp. 35-43. Para datos más actualizados, véase Buiguìs, Jean Marc. "Les traductions dans l'Espagne des Lumiéres: langues, rythmes et contenus». Bulletin Hispanique, 2002, 1, pp. 101-119.

9. LASA ÁlVAREZ, Begoña. "Los traductores franceses como intermediarios culturales durante el siglo XVIII y su vigencia en la actualidad». En LAFARGA, Francisco; LlORCA, Ángeles y SiRvENT, Ángeles (eds.). Le XVIIIe siècle aujourd'bui: présences, lectures et réécritures. París: Le Manuscrit, 2011, pp. 273285. Un somero y actualizado panorama sobre la labor traductora de la literatura italiana en la España del XVIII puede consultarse en mi reciente trabajo: "La traducción de las letras italianas en el siglo XVIII». En Lafarga, Francisco y Pegeneaute, Luis (eds.). Historia de la traducción en España. Siglo XVIII. Universitat Pompeu Fabra, 2021. http://phte.upf.edu/hte/siglo-xviii/quinziano/

10. ARCE, Joaquín. La poesía del siglo ilustrado. Madrid: Alhambra, 1981, pp. 88-89. 
patrimonio lingüístico, aunque su incidencia, desde ya, fue mucho menor respecto a la 'invasión' de vocablos franceses. Las numerosas aportaciones críticas sobre las traducciones de textos literarios italianos en el setecientos que han visto la luz en los últimos años -registradas en la exhaustiva bibliografía compilada por Lafarga e incluida en el Portal de la Biblioteca Virtual Miguel Cervantes- hablan asimismo de un terreno fértil, organizado en torno a un virtuoso abanico de contactos, influjos y recepciones, en el que el género teatral domina de modo incontrastable.

\section{TRADUCCIÓN EN EL CAMPO TEATRAL}

La traducción en el ámbito teatral constituye uno de los campos mayormente explorados por la crítica. El horizonte de la actividad traductora de textos italianos en la España del siglo XVIII constituye asimismo un campo fértilmente abonado, pudiéndose reconocer significativas aportaciones que han arrojado nueva luz en especial sobre los tres autores emblemas del Settecento italiano: Metastasio, Goldoni y Alfieri. Los dos primeros nombres son los mayormente traducidos a lo largo del siglo y sus obras alcanzan una indudable resonancia en los escenarios del periodo, mientras, como se ha precisado arriba, la recepción del tragediógrafo de Asti apenas ocupa la época aquí estudiada. La presencia de textos de estos autores constituye sin duda un eslabón decisivo para comprender la importancia y la función que, en el marco de las relaciones hispano-italianas e ítalo-españolas, revistió el teatro en la plasmación del fértil diálogo entre ambas penínsulas hespéricas, como así también en el intercambio y circulación de temas, gustos y tendencias ${ }^{11}$.

El investigador tiene a su disposición algunos meritorios trabajos orientados a catalogar y poner orden en esta significativa producción de obras italianas traducidas en el Siglo de las Luces. Después del ya lejano y revisable trabajo de Parducci $^{12}$, más recientemente han visto la luz dos catálogos de gran utilidad que revisan y completan ampliamente los precedentes repertorios y resultan materiales de consulta obligada: nos referimos a la catalogación de las tragedias italianas, compilada por Garelli ${ }^{13}$, y el que se ocupa de las comedias italianas, redactado

11. Para los intercambios e influjos en el XVIII entre ambas penínsulas en campo teatral, véanse Quinziano, Franco. "Senderos de ida y vuelta. España e Italia en el Siglo de las Luces (1700-1759): itinerarios, presencias y recepciones culturales". The Korean Journal of Hispanic Studies, 2009, 2, pp. 185-199, y FABBri, Maurizio. "Il ruolo del teatro nelle relazioni culturali tra Italia e Spagna nel secolo XVIII". En Il teatro dimenticato. Note su testi minori del Settecento spagnolo. Rimini: Panozzo, 2016, pp. 101-109.

12. PARDUCCI, Amos. "Traduzioni e riduzioni spagnole di drammi italiani». Giornale Storico della Letteratura Italiana, 1941, 117, pp. 98-124.

13. Garelli, Patrizia. "Traducciones de tragedias italianas». En LAFArGa, Francisco (ed.). El teatro europeo en la España del siglo XVIII. Lleida: Universitat de Lleida, 1997b, pp. 325-363. 
a cuatro manos por Calderone y Pagán ${ }^{14}$. Estos inventarios, que incluyen las traducciones datadas hasta 1808, evidencian el indiscutible dominio alcanzado por Metastasio y Goldoni en los escenarios españoles, constituyendo ambos autores casi el $90 \%$ del total del repertorio teatral peninsular traducido o adaptado al español. Se dispone asimismo de tres tesis doctorales que incluyen un listado actualizado sobre las traducciones y representaciones referidas a Metastasio y Goldoni y que complementan los citados inventarios, de carácter más general ${ }^{15}$. Además de estas herramientas imprescindibles, de gran ayuda para despejar dudas y repeticiones, resulta el catálogo del Proyecto Boscán (www.ub.edu/boscan/), dirigido por Muñiz-Muñiz, con más de 800 entradas por autor, título original y de la traducción/adaptación, traductor y fecha, útil asimismo para solventar problemas de cronología y autoría.

No debe olvidarse que, al hablar de "traducción teatral» en el XVIII, se alude a un proceso complejo que concedía diversos niveles de libertad al traductor y que implicaba en la mayoría de los casos la reelaboración o recreación del texto original a una nueva versión en la que se podía cambiar el género (del verso a la prosa o viceversa), suprimir personajes y escenas en función de los propósitos del adaptador, cambiar o sustituir el número de escenas, enfatizar algunos ejes temáticos y argumentales en desmedro de otros en función del nuevo público, etc. Quien se proponga abordar la traducción en ámbito teatral, debe tener en cuenta asimismo otros materiales que pueden proporcionar un panorama más pertinente y exhaustivo, como las carteleras del periodo, la crítica (reseñas y comentarios en la prensa cultural), las cronologías y biografías, los gustos del público y la labor y el estado de la censura; factores estos últimos que en cierto modo influyeron o condicionaron las elecciones y estrategias adoptadas en la actividad traductora.

No son pocos por demás los obstáculos que deben solventar quienes se propongan abordar el estudio de los textos teatrales traducidos y poner claridad en la selva de obras extranjeras vertidas a nuestra lengua en el setecientos: en primer lugar, no debe olvidarse que muchas veces no aparecía en la traducción el título de la obra original, así como no fueron pocas las piezas que se tradujeron y subieron

14. Calderone, Antonietta y PagÁn, Víctor. "Traducciones de comedias italianas». En LaFARGA, Francisco (ed.). Op. cit., 1997, pp. 139-181.

15. Véanse, respectivamente, las tres tesis doctorales: RodríGuez Alonso, Manuel. De la ilustración al romanticismo: Teatro y espectáculo italianos en España a caballo entre los siglos XVIII y XIX en las figuras de Pietro Metastasio y Vittorio Alfieri. Granada: Universidad de Granada, 2015, pp. 113-128; Rodríguez Gómez, Inés. Las obras de Carlo Goldoni en Espanya (1750-1800). Valencia: Universitat de València, 1997, pp. 664-723, y PAGÁN, Víctor. El teatro de Goldoni en España. Comedias y dramas con música entre los siglos dieciocho y veinte. Madrid: Universidad Complutense de Madrid, 1997b, pp. 281480 y 486-512. Pagán incluye 104 títulos que se conservan «en español de comedias y tragicomedias que se distribuyen de la siguiente forma: 68 del siglo dieciocho, 7 del diecinueve y 29 del veinte. Esta lista corresponde a 59 títulos originales del autor italiano y no a adaptaciones de las mismas"; op. cit., 1997b, p. 484. El investigador ha localizado asimismo 48 dramas para música, de los que 12 son traducciones en español y una veintena publicadas en ediciones bilingües. 
a los escenarios con nombres distintos y en sucesivas y diversas versiones respecto a la primera traducción, muchas veces con títulos similares entre sí, si no idénticos, y amoldadas a diversos subgéneros dramáticos. Asimismo -especialmente en las de encargo-, solía no aparecer el nombre del traductor, con los consiguientes problemas de atribución; en otras ocasiones se hace difícil determinar la fecha de redacción, presentando todo ello no pocos problemas, tanto cronológicos como estilísticos. Las modificaciones de los títulos de las versiones españolas muchas veces se hallan asociadas a las nuevas cargas de intencionalidad que quiere asignarle el traductor o adaptador a la pieza, ante la presencia de un nuevo público, acentuando por ejemplo o bien su propósito de carácter moral o bien de crítica de determinados tipos y modelos de comportamiento, para adecuarse al gusto del público, en el marco de la finalidad educadora y de exemplum que caracteriza el drama en la centuria.

\section{METASTASIO Y EL MELODRAMA ITALIANO: ENTRE LA TRADUCCIÓN Y LA ADAPTACIÓN}

Metastasio, autor del que se han volcado al español en diversos periodos unos 150 melodramas, se incorpora como poeta cesáreo en la corte de Viena en 1730, sustituyendo a su compatriota Apostolo Zeno, de quien hereda la vocación hacia la reforma del melodrama en sentido clasicista y racional. Es posible rastrear la presencia de temas y modelos derivados del drama aurisecular español en ambos autores, lo que facilitó en cierto modo la penetración y recepción de sus obras en la península ibérica. Del dramaturgo veneciano, quien asigna dignidad literaria al drama musical, el Proyecto Boscán recoge hasta ahora unas 17 traducciones al español, siendo por lo general sus obras traducidas y representadas tardíamente, a lo largo del último tercio del siglo, cuando Metastasio había triunfado ya en los coliseos de la península.

Entre otros textos, se vierten al español sus comedias heroicas Gianguir (1724) y Euristeo (Antígona y Euristo, 1769), adaptada esta última por Ramón de la Cruz, así como sus dramas en música El Venceslao en 1754 (Venceslao); Zenobia de Palmira (Zenobia in Palmira, con Pariati); Pirro, representada en Madrid en 1793; otra traducción libre de la misma pieza a cargo de Rodríguez de Arellano, Pirro y Casandra (1798), y El Bologeso (Vologeso, re dé Parti), representada en Cádiz en 1769. En Madrid se representaron asimismo sus tragedias Sesostris, rey de Egipto en octubre de 1766 (Sesostris) y Licio Papirio, dittatore, bajo el título de El severo dictador y vencedor delincuente (1791), traducidas ambas también por el sainetista madrileño, sin olvidar su afamada Ifigenia in Aulide, escenificada en 1755 en Barcelona. De estos datos, aunque provisorios ${ }^{16}$, no cabe duda de que

16. Debe lamentarse la ausencia aún de estudios dedicados al dramaturgo veneciano en el panorama de los estudios sobre las traducciones teatrales en el dieciocho: la exhaustiva y actualizada bibliografía compilada por Lafarga, http://www.cervantesvirtual.com/nd/ark:/59851/bmckh127, no 
los melodramas de Zeno, considerado el maestro de Metastasio, no alcanzaron en España la resonancia que obtendría su discípulo, siendo su obra, como indica Garelli, conocida y apreciada "por el público español en muy menor medida"

Mucho más decisivas han resultado sin duda la presencia y la recepción del drama de Metastasio a lo largo de la centuria. Para ceñirnos solo a los escenarios madrileños, la cartelera de Andioc-Coulon registra unos 30 títulos, entre obras traducidas, adaptadas, refundidas e imitadas, de incuestionable derivación metastasiana, superando sus piezas, en el periodo entre 1736 y 1806, el centenar de representaciones ${ }^{18}$. Como se ha apuntado, muy aplaudidas fueron especialmente Acrisolar la lealtad, el Siroe, No hay en amor finezas (ambas con al menos seis representaciones), Demofonte, rey de Tracia, Clelia (triunfante en Roma), con siete funciones cada una. La ópera La Niteti registró al menos ocho representaciones en los Caños del Peral, mientras que Ser vencido y vencedor, Julio César y Catón y Talestris, reina de Egipto, llegaron a subir a los escenarios de la capital, respectivamente, en nueve y diez ocasiones a lo largo del último cuarto de siglo y los inicios del $\mathrm{XIX}^{19}$

Su modelo dramático representó el inicio de la exitosa etapa del italianismo musical en los teatros de España, abriendo camino a la introducción, entre otros, de los dramas cantados de Da Ponte, Calzabigi, Lorenzi y Bertati. La ópera metastasiana fue asimismo canal de penetración de no pocos vocablos y expresiones italianas que se incorporaron y se asentaron plenamente en nuestro idioma, al tiempo que su difusión, con la incorporación de temas y personajes míticos o heroicos, ejerció también su influencia en la configuración de la tragedia española de la segunda mitad del siglo, género que, a diferencia de lo que un sector de la crítica ha supuesto, no era ajeno a la tradición literaria española: como se ha observado, el melodrama metastasiano desempeñó «un papel que no fue ciertamente marginal en la renovación del teatro español del Setecientos ${ }^{20}$.

La penetración y el éxito del drama metastasiano en España, imponiendo la moda del melodrama, se hallan asociados a la llegada a la corte española en 1737 del cantante Carlo Broschi (Farinelli), amigo del dramaturgo romano y protegido de la reina consorte Isabel de Farnesio. Farinelli llegó a ejercer una enorme

registra ningún estudio crítico dedicado a Zeno en la España del periodo, constituyendo a día de hoy una laguna a la espera de que próximas investigaciones puedan colmarla.

17. GARELli, Patrizia. "Metastasio y el melodrama italiano». En LAFARGA, Francisco (ed.). El teatro europeo en la España del siglo XVIII. Lleida: Universitat de Lleida, 1997a, p. 127.

18. ANDIOC, René y COUlon, Meirelle. Cartelera teatral madrileña del siglo XVIII (1708-1808). 1. ${ }^{a}$ ed. Toulouse: Press Universitaries du Mirail, 1996.

19. QuinZIano, Franco. España e Italia en el siglo XVIII. Presencias, influjos y recepciones. Barañáin: EUNSA, 2008, p. 55.

20. GARelli, Patrizia. "Dos adaptaciones de Didone abbandonata de Pietro Metastasio en el teatro español de la segunda mitad del siglo XVIII». En LAFARGA, Francisco y Dengler, Roberto (eds.). Teatro y Traducción. Barcelona: Universitat Pompeu Fabra, 1995, p. 107. 
influencia durante los últimos años del reinado de Felipe $\mathrm{V}$ y de modo más acusado en los años de su sucesor Fernando VI, como encargado de los espectáculos lírico-dramáticos y fiestas palaciegas en el teatro del Buen Retiro. Son esos lustros, entre 1750 y 1770, los que encarnan el momento de mayor esplendor del melodrama metastasiano en España, pero cuyas bases se hallan sólidamente asentadas en la primera mitad del siglo.

Es posible formarse una idea de la fama del modelo dramático-lírico del poeta romano en el teatro cortesano del periodo, si se recuerda que cualquier ocasión -el cumpleaños del rey o la reina consorte; un bautismo; una boda real, como la de los príncipes de Asturias; un aniversario; una fiesta palaciega o carnaval- era un pretexto para que dicho acontecimiento o celebración se solemnizara en el teatro del Buen Retiro con la representación de un melodrama del autor romano. Esta fecunda recepción del «inmortal Metastasio», como solía llamarle Leandro Moratín ${ }^{21}$, se halla ampliamente documentada y su prestigio en las letras hispánicas se mantiene vivo hasta bien entrado el siglo XIX. Son innumerables los comentarios elogiosos que preceptistas, críticos y dramaturgos españoles del periodo le dedican, desde Luzán hasta Leandro Moratín, pasando por los jesuitas expulsos Andrés, Eximeno y Arteaga.

El catálogo compilado por Garelli ${ }^{22}$ registra más de medio centenar de traducciones y adaptaciones referidas a unos 40 títulos suyos; no son pocas las piezas que reconocen más de una versión al español, en varios casos con modificación de los títulos y en general prescindiendo de las anteriores versiones. Por su parte, el catálogo del Proyecto Boscán registra algo más de 230 entradas de piezas metastasianas, de las que unas 200 corresponden a traducciones, adaptaciones, nuevas ediciones y reimpresiones en español relativas a medio centenar de sus dramas (www.ub.edu/boscan). El catálogo constituye una herramienta muy útil para despejar posibles duplicaciones, errores, dudas y lagunas; por otro lado esta amplia presencia, que supera los doscientos títulos, atestigua la vigencia y popularidad del autor romano en los escenarios españoles.

Como ha indicado Garelli, "la multitud de libretos [...] vertidos al castellano con varias denominaciones -opera dramática, drama en música, melodrama armónica, etc.-, se debe al hecho de que, a menudo, un mismo texto, tras su estreno, volvía a traducirse al castellano al ser musicado por un compositor distinto ${ }^{23}$. Ello conlleva la necesidad de examinar y cotejar cambios, supresiones y añadidos entre las diversas versiones. Existen algunas aportaciones en dicha perspectiva, como

21. Fernández de Moratín, Leandro. Viage a Italia. Belén Tejerina (ed.). Madrid: Espasa-Calpe, 1988 , p. 291.

22. Garelli, Patrizia. Op. cit., 1997b, pp. 325-363

23. Garelli, Patrizia. «Metastasio, Pietro». En Lafarga, Francisco y Pegenaute, Luis (ed.). Diccionario Histórico de la Traducción en España. Madrid: Gredos, 2009, p. 783. http://phte.upf.edu/dhte/ italiano/metastasio-pietro 
por ejemplo el mencionado estudio de Garelli (1995), dirigido a explorar dos versiones distintas de una de sus obras más exitosas, Didone abbandonata.

Desde el lejano estudio de Sterling Stoudemire, que vio la luz en 1941, mucho se ha avanzado sobre el abordaje de las piezas metastasianas en España, con copiosas aproximaciones sobre esta relevante presencia en los escenarios españoles de la centuria. Sin embargo, entre otras tareas pendientes, se echan en falta más estudios en clave comparada sobre diversas versiones de un mismo texto original, como así también un análisis de conjunto de la ingente labor traductora que nos ha legado Benito de Céspedes, correspondiente a casi una treintena de melodramas, que permanecen aún manuscritos, y de la que que se dispone por ahora tan solo de una primera -y parcial- aproximación de Martín Puente ${ }^{24}$.

Por lo que concierne a los traductores o adaptadores que vierten los libretos del afamado autor romano, una parcela relevante ha quedado en el anonimato. Posiblemente varias de estas versiones, aún anónimas, hayan sido confiadas para su traslado al español a la labor del médico personal de Farinelli, Orlando Buoncore, durante el periodo en el que el castrato se desempeñó como director de los teatros reales. En la lista de traductores confirmados es posible reconocer a algunos autores consagrados, como Luzán y Ramón de la Cruz, pero también dramaturgos menos célebres, algunos de ellos de menor rango, aunque con una nada desdeñable trayectoria detrás, como Zavala y Zamora, Luis Moncín, Trigueros o Ignacio García Malo, quienes beben de las fuentes metastasianas para incrementar el repertorio teatral.

Ramón de la Cruz, cuya importancia como traductor y difusor del teatro italiano ha sido estudiada por Meregalli y Garelli ${ }^{25}$, destaca como adaptador de dramas metastasianos, contando en su haber con una decena de versiones al español. Otros dramaturgos que se interesan en traducir obras del autor romano son Trigueros (La muerte de Abel), M. F. Laviano (La isla desierta), López de Sedano (Ser vencido y vencedor, Julio César y Catón), Rodríguez de Arellano (Temístocles; Dido abandonada; La Atenea; Semíramis reconocida), García Malo (Demofonte, rey de Tracia), Moncín (Ambición, riesgo y tradición vence una mujer prudente) y el periodista y preceptista Mariano Nifo (Hypsípyle; No bay en amor finezas). Otras veces son los cómicos de las compañías quienes trasladan algunas piezas, como Vicente Camacho (Por amor y por lealtad; 1736) o Manuel Guerrero, quien vierte el drama para música L’Olimpiade, con el más extenso título La más heroica amistad y el amor más verdadero (1745). En otras ocasiones la labor le es

24. MARTin Puente, Cristina. "Las obras sobre la historia de Roma de Metastasio y sus traductores al español con atención al jesuita Benito Antonio de Céspedes». Cuadernos de Investigación Filológica, 2013, 39, pp. 187-204.

25. Meregalli, Franco. "Goldoni e Ramón de la Cruz". En Branca, Vittore y Mangini, Nicola (eds.). Studi goldoniani. 2 vols. Venecia: Istituto per la Collaborazione Culturale, 1960, II, pp. 795-800; Garelli, Patrizia. "Ramón de la Cruz, adaptador de melodramas metastasianos». En Sala VAlldaura, Josep M. ${ }^{a}$ (ed.). El teatro europeo del siglo XVIII. Lleida: Universitat de Lleida, 1996, II, pp. 447-473. 
encomendada incluso a algún funcionario de la Corona, como Jerónimo Val, secretario del Consejo de Castilla, quien, por encargo de la misma reina, traduce en 1738 Alejandro en las Indias.

Estas versiones son muy dispares entre sí: si en varias ocasiones la traducción o la adaptación, sin esconder la interpretación personal de quien acomete la labor, exhibe pericia lingüística, respetando las expresiones y los valores semánticos, así como la fábula, del libreto original, en otras resulta evidente la escasa calidad de la traducción. Ejemplo de esto último es el Demofoonte, texto volcado al español en 1738 por un traductor anónimo, que exhibe varios defectos respecto a la versión italiana. Las prisas y la abundancia de piezas metastasianas por trasladar al español para ser representadas en breves intervalos de tiempo, y que redundan en no pocas traducciones defectuosas o de escasa calidad, lleva a que algunos preceptistas y críticos, como Estala y Vargas Ponce, pongan en sus críticas el acento en las deficiencias de estas traducciones de los libretos del autor italiano.

Respecto a la primera versión anónima del Demofoonte, sus defectos suscitarán muchos años después, en 1791, una severa crítica y censura de la crítica, dando lugar a uno de los numerosos casos de retraducción. En dicha perspectiva García Malo se propone acometer, como confiesa en el prólogo que antepuso a su versión, una nueva traducción para subsanar la pobre calidad lingüística y los criterios estéticos adoptados, por él considerados inadecuados ${ }^{26}$.

A partir de la segunda mitad de los años '30 del XVIII es posible reconocer una cada vez mayor presencia de obras del "Príncipe de los poetas dramáticos modernos", como lo bautizó Feijoo ${ }^{27}$, en español. Estas piezas comienzan a representarse en los teatros públicos de Madrid, para luego difundirse en los coliseos de las ciudades de la periferia (Valencia, Barcelona, Sevilla o Cádiz). En 1737 las autoridades acometen una profunda renovación del coliseo de los Caños del Peral, siguiendo proyectos de los arquitectos italianos Galluzzi y Bonavia; un año después, por iniciativa de Farinelli, se reforma ampliamente también el sitio del Buen Retiro, para adaptar el teatro cortesano a la escena lírica. Su inauguración da inicios a la "era Farinelli», erigiéndose en el coliseo en espacio privilegiado para la representación de los espectáculos dramático-musicales que tiene en el melodrama metastasiano, a cargo de la nueva compañía italiana de actores, su consagrada fórmula de éxito y popularidad.

Lafarga recuerda que «el melodrama italiano terminó siendo en España un género de éxito popular, en parte debido a las modificaciones introducidas por los traductores españoles ${ }^{28}$. Los melodramas se hallan vinculados a la idea de gran espectáculo encomendado a los prestigiosos escenógrafos italianos, en el

26. Ver Lafarga, Francisco. Op. cit., 2004, p. 217.

27. FEIJOO, Benito J. "El deleyte de la Música”. En Cartas curiosas y eruditas. Madrid: A. Pérez de Soto, 1765, volumen IV, carta I, p. 17.

28. Lafarga, Francisco. Op. cit., 2004, p. 273. 
que la decoración teatral y la adopción del uso de máquinas y tramoyas desempeñan una función primordial, garantizando la segura atracción del público. Es esta orientación hacia la espectacularidad y lo maravilloso, acentuada en el teatro español de corte del siglo XVIII, como se ha observado ${ }^{29}$, la que determina la explícita enumeración y referencias en los textos de las adaptaciones españolas de las mutaciones de la escena, más escuetas en cambio en los libretos italianos. La presencia de figuras míticas e históricas constituye otro elemento de novedad en estas piezas dramático-musicales (Dido, Semíramis, Astaserse, Alejandro, Adriano), al tiempo que la fórmula musical y escénica metastasiana irradia «una auténtica fuente de símbolos y de imágenes que cimentan lo que es la base progresiva y culta del movimiento teatral cortesano de la segunda mitad del siglo XVIII ${ }^{30}$, renovando la escena española.

Será a partir de la llegada de Farinelli y después de la renovación de los teatros de Caños del Peral y del Buen Retiro, cuando se asista de modo continuo a la puesta en escena de los melodramas del autor romano. La serie se abre con La clemenza di Tito (1734), cuya traducción de 1739 se halla a cargo de Félix Quazza. Cuando vuelve a representarse en 1747, abriendo la brillante fase del melodrama en el sitio del Buen Retiro, la traducción la acomete Luzán, versión ampliamente elogiada por Moratín, mientras que, en los límites cronológicos de nuestro periodo, en plena guerra de la Independencia, es posible encontrar una nueva adaptación, como comedia heroica, a cargo del dramaturgo Zavala y Zamora. Teniendo en cuenta la poca estimación que Luzán manifestó en su Poética al teatro musical, sorprende que acometiese la traducción del melodrama italiano. Poco amante del melodrama, aunque apreciaba a Metastasio por sus virtudes como poeta lírico y dramático (en sus años en Nápoles había traducido el Artajerjes y redactado también un elogio del poeta cesáreo), eximio conocedor de la lengua italiana, habría aceptado el encargo por obediencia a los designios del marqués de Ensenada ${ }^{31}$.

29. ProfetI, Maria Grazia. "Metastasio in Spagna all'inizio del secolo XVIII". En Commedie, riscritture, libretti: la Spagna e l'Europa. Florencia: Alinea, 2009, p. 273. Los libretos de ópera, observa con perspicacia la hispanista italiana, "nascono e si adattano alle circostanze, all'acustica, alle messe in scena, in una parola, ai luoghi teatrali, luoghi che selezionano anche il loro destinatario", p. 232.

30. Chaves Montoya, Teresa y DE la Flor, Fernando. "Teatro musical». En CARNERo, Guillermo (ed.). Historia de la literatura española. Siglo XVIII (I). Madrid: Espasa-Calpe, 1995, pp. 378-379.

31. FERnÁNDEZ FERnÁNDEZ, Olga. "La clemencia de Tito de Metastasio en la traducción de Luzán y la visión de la ópera a través de los neoclásicos españoles del siglo XVIII». Dieciocho, 2001, 24.2, pp. 218-219. Se ha observado que "habrá que esperar a la edición de París de 1757 y a la de Niza de 1783, revisadas por el autor, para poder tener un texto que permita hacer un cotejo entre los textos italianos, los de la edición parisina y nizarda, y los dos traducidos por Quazza y Luzán respectivamente. [...] Es fácil ver que el texto manejado por Luzán es un texto más completo, a pesar de estar ligeramente abreviado”, FERnÁndez FERnÁndez. Op. cit., 2001, pp. 237-238, nota 4. MCClelland destaca la alta calidad de la traducción luzaniana, situándola muy por encima de la de Quazza, más literal y menos expresiva: Ignacio de Luzán. Nueva York: Twayne Publishers, 1973, p. 67. Sobre la traducción de Zavala y Zamora véase FERNÁNDEZ CABEZón, Rosalía. "Influencia de Metastasio en la comedia heroica de Gaspar Zavala y Zamora". Anuario de Estudios Filológicos, 1989, 12, pp. 81-87. 
Entre 1736 y 1738 suben al escenario en los teatros públicos (Príncipe, de La Cruz y especialmente Caños del Peral), las piezas del autor italiano que signan el inicio de este brillante momento del género basado en la colaboración entre traductores españoles y músicos italianos: un mismo día, el 31 de enero de 1736, se representan Dar el ser el hijo al padre (Artaserse), traducida por Guerrero, y Por amor y por lealtad y Demetrio en Siria (Demetrio), vertida al español por el actor Camacho y donde hace su aparición el gracioso de la comedia áurea ${ }^{32}$. Un año más tarde se escenifican Amor, constancia y mujer (Siface) y Adriano en Siria (Adriano in Siria), traducida esta última por Bazano. En 1738 se estrenan Alejandro en las Indias (Alessandro nelle Indie), primera representación palatina que tiene lugar en el reformado coliseo real del Buen Retiro ${ }^{33}$, y El Demofoonte, que se escenifica en los Caños del Peral. Estos últimos dos libretos inician la larga serie de versiones metastasianas con el testo a fronte, en versión bilingüe italiano y español. La serie de representaciones a cargo de Farinelli como organizador de los espectáculos dramático-musicales de la Corona se cierra con Adriano en Siria en septiembre de 1757, constituyendo el mismo una de las grandes -y últimaspiezas melodramáticas durante el reinado de Fernando VI.

Por lo general estas versiones, por lo que concierne a la fábula, no presentan variantes de relieve respecto al original. La fidelidad concernía en tener presentes, a la hora de volcar la pieza al español, el léxico, la gramática, la retórica, el estilo y la estructura de la obra. Leza y, de modo más exhaustivo, Profeti ${ }^{34}$ se han ocupado de estas tempranas composiciones lírico-musicales, estudiando las modalidades de penetración del drama de Mestastasio en la España de Felipe V y atendiendo al contexto en que las mismas se representaron en los teatros públicos y de corte madrileños.

En los inicios puede apreciarse la voluntad de los traductores en ser respetuosos al sentido de los textos, aunque no fueron una excepción quienes optaron por plasmar una adaptación más que una traducción fiel, orientando sus elecciones a satisfacer el gusto del público madrileño. Así, por ejemplo, en el prólogo que precede a la versión de Demetrio puede leerse que «Metastasio inventó esta ópera al estilo y con el idioma de Italia, pero Camacho -el traductor- la ha dispuesto de suerte, que verdaderamente la ha hecho suya ${ }^{35}$. Respecto a las alteraciones que establece en su recreación teatral Camacho, cómico de teatro, puede reconocerse, por ejemplo, el añadido de la escena del naufragio en el primer acto, lo que provoca un cambio dramático de la puesta en escena de dos de los personajes centrales, Alceste y su criada Cascuncia.

32. BALDISSERA, Andrea. "Metastasio en España, entre traducciones y refundiciones». Boletín de la Biblioteca de Menéndez Pelayo, 2007, LXXXIII, p. 157.

33. Profeti, Maria Grazia. Op. cit., 2009, pp. 257-265.

34. LEZA, José M. ${ }^{\mathrm{a}}$. "Metastasio on the Spanish stage: Operatic adaptations in the public theatres of Madrid in the 1730s». Early Music, 1998, XXVI. 4, pp. 623-631, y ProfETI, Maria Grazia. Op. cit., 2009.

35. Cit. en LEZA, José M. ${ }^{a}$. Op. cit., 1998, p. 627. 
La incorporación del gracioso, fuertemente anclado en la tradición del drama áureo español, más instrumental que personaje con entidad propia, constituye otra de las variantes en estas tempranas traducciones, como se desprende de $D e$ metrio (Por amor y por lealtad) y Siface (Amor, constancia y mujer). Juntamente a la incorporación del gracioso, que acabará desapareciendo a medida que avanza la centuria, es posible reconocer la eliminación de escenas o diálogos entre personajes de menor entidad, así como la supresión de algunas arias, con el fin de abreviar y adecuar los espectáculos a la duración máxima estipulada de dos horas. Algunos de los nuevos rumbos que adoptan las traducciones de libretos metastasianos hablan de la ausencia de la motivación ética presente en sus piezas, de diferencias en el modo de concebir el carácter de los personajes, así como la menor entidad psicológica que exhiben algunos de ellos, erigidos en un nuevo tipo de héroes, y del que el Eneas de Ibáñez y Gassía (El valiente Eneas, 1757) distanciado del protagonista de Didone abbandonata, que constituye su fuente, resulta un caso significativo ${ }^{36}$.

La reducción de las tramas y el uso del verso octosilábico, en lugar de la polimetría, conjuntamente con el propósito moral, son otras de las soluciones adoptadas por los traductores. En algunas ocasiones la traducción privilegia la modernidad de la prosa en lugar del verso del original, aunque, respecto a otros autores y formas dramáticas del siglo, las versiones españolas de las obras del romano por lo general respetaron el verso, con algunas contadas excepciones mayormente presentes hacia finales del siglo- como por ejemplo Trigueros, quien prefiere la prosa por su carácter conversacional y más acorde para representar la vida cotidiana.

A partir de la segunda mitad del siglo, y de modo más acusado en los últimos decenios, se asiste a una mayor propensión a acometer libres adaptaciones que se alejan parcialmente del modelo metastasiano. Es posible ejemplificar este proceso apelando, una vez más, al virtuoso estudio comparativo de Garelli ${ }^{37}$, dedicado a la afamada pieza Didone abbandonata. El melodrama, traducido fielmente y editado en versión bilingüe, sube a escena en 1752, primero en Barcelona y sucesivamente en Madrid. A lo largo de la segunda mitad ven la luz varias adaptaciones libres, confirmando la vigencia en el teatro español del mito de la reina de Cartago. Es posible localizar diversas versiones del melodrama original, entre las que destacan, además de la primera anónima y de otra acometida por Céspedes ${ }^{38}$, otras dos adaptaciones: el ya citado El valiente Eneas (1755), de Ibáñez y Gassía, y Dido

36. Garelli, Patrizia. Op. cit., 1995, pp. 100-102.

37. Garelli, Patrizia. Op. cit., 1995.

38. MARTín PuENTE afirma no tener certezas sobre si la traducción manuscrita de Céspedes de Dido abandonada es anterior o posterior a la que se representa en 1752 en Barcelona, como tampoco si precede o es posterior a El valiente Eneas, de Ibáñez y Gassía de mediados de la centuria; asevera sí que con toda probabilidad es anterior a la adaptación de Rodríguez de Arellano, que se representó en 1795; op. cit., 2013, p. 198. 
abandonada, pieza heroica de Rodríguez de Arellano, llevada a escena en 1795. Las dos versiones reflejan la evolución del gusto del público y confirman la perenne vigencia del mito virgiliano en la cultura española; ambas constituyen solo un ejemplo de las múltiples variantes que presentan los procesos de retraducción, adaptación y refundición del drama metastasiano a lo largo del último tercio de la centuria para adecuarse al público español.

Con la llegada al trono de Carlos III, el melodrama como género reconoce una menor presencia en los escenarios. El vasto repertorio a la italiana se reduce a la representación de dramas jocosos, aunque en los últimos dos decenios del siglo se asiste a una renovada presencia del teatro musical, que cobra nuevo esplendor, gracias al auge de los melólogos (Zavala y Zamora, Rodríguez de Arellano y Comella, entre otros) y a la difusión de los géneros de la zarzuela y la comedia heroica. En este renovado empeño por aproximar al público temas y personajes del drama metastasiano, connaturalizándolo a la escena nacional, destaca la figura de Cruz, quien, además de componer sainetes, se prodiga en escribir versiones nacionales de óperas italianas, convirtiéndolas en zarzuelas al gusto barroco, al transformar los recitativos en declamados y resaltando la función didáctica y los aspectos morales de sus piezas.

Como se ha indicado, la labor de la Cruz «es más creativa que la meramente traductora, pues consiste en la reescritura de una pieza a partir de elementos tomados de otra, con todo un trabajo de adaptación cultural, ${ }^{39}$. Su importante labor sanciona un renovado interés hacia el teatro del autor romano en los últimos tres decenios del XVIII, itinerarios que transitarán también otros dramaturgos de oficio, que conocen muy bien los gustos y los resortes del público, como -entre otros- Zavala y Zamora, Rodríguez de Arellano, Bazo y Trigueros. Estos autores, ante la fuerte demanda por ampliar el repertorio y disponer de obras para su representación, se empeñan en verter y adaptar obras extranjeras, escogiendo el melodrama metastasiano como fuente privilegiada para sus dramas en busca de un nuevo repertorio teatral ${ }^{40}$. Se asiste así en los últimos decenios de la centuria e inicios del XIX a un proceso de adaptación que convierte las óperas italianas, principalmente, en óperas 'azarzueladas', basadas en el despliegue de una portentosa escenografía y ostentosos decorados. De este modo, el teatro musical de Metastasio, concebido como gran espectáculo, alcanza una notable resonancia entre el público español en los últimos lustros del siglo que se proyecta hasta los primeros años del XIX.

39. Lafarga, Francisco. "La comedia francesa». En Lafarga, Francisco (ed.). Op. cit., 1997, p. 103.

40. Un panorama general sobre la formación del nuevo repertorio procedente del teatro extranjero en Palacios, Emilio. "El teatro en el siglo XVIII (hasta 1808)». En Díez BorQue, José M. ${ }^{a}$ y SuRTZ, Ronald (eds.). Historia del teatro en España: siglo XVIII, siglo XIX. Madrid: Taurus, 1983, II, pp. 233-255. 


\section{PRESENCIA y RECEPCión DEL TEATRO DE CARLO GOLDONI}

Goldoni, quien en diversas ocasiones explicitó su deuda y admiración hacia el drama español áureo, en especial hacia Lope de Vega, es el autor italiano más traducido en la España del XVIII. El veneciano constituye uno de los primeros dramaturgos en erigirse en un fenómeno europeo; sus piezas han sido las que fueron representadas con mayor éxito fuera de las fronteras de su país, en su mayoría adaptadas libremente. Sus obras, cuyo ingreso a los teatros de España es posible registrar en los años centrales del siglo XVIII, durante los últimos años del reinado fernandino, proponen la configuración de una nueva preceptiva dramática, orientada a la promoción de reformas en los escenarios italianos, y se hallan dirigidas a suprimir gradualmente los canovacci y los modelos ya predeterminados de las máscaras de la commedia all'improvvisa.

La crítica ha explorado esta importante presencia en los escenarios españoles, habiendo concitado la temprana atención de Rogers, Parducci y Mariuttí1 ${ }^{4}$. Más recientemente, las diversas aproximaciones de Calderone y Pagán constituyen aportaciones obligadas a las que acudir para abordar el drama goldoniano en la península, habiendo colmado ambos investigadores varias de las lagunas presentes en los precedentes estudios, al tiempo que ofrecen un cuadro más completo e iluminador de los diversos itinerarios por los que transitó la recepción del veneciano. La introducción de Goldoni en la península ibérica se inicia en los años centrales de la centuria para alcanzar su definitiva consagración en la última década, cuando, como recordaba Leandro Moratín, sus obras en cambio se habían «hecho ya bastante raras en los teatros de Italia " ${ }^{42}$.

Esta presencia del drama goldoniano es deudora, en especial por lo que concierne a sus dramas jocosos, a la familia real (en primer lugar a los príncipes de Asturias, aficionados a los espectáculos teatrales y musicales, más que Carlos III, poco entusiasta en verdad de la música y el teatro). El mercado musical de Madrid y Barcelona promovió la entrada gradual de sus drammi giocosi, siendo, para el caso madrileño, la fase de mayor intensidad precisamente los últimos lustros del siglo. A principios del siglo XIX sus piezas aún superaban el medio centenar de representaciones, la mitad de ellas durante el trienio inmediatamente precedente a la guerra de la Independencia (1805-08). En esos años de entresiglos sus obras

41. Rogers, Paul. Goldoni in Spain. Oberlin (Ohio): The Academy Press, 1941; Parducci, Amos. op. cit, 1941 y MARIUTTI DE SÁnChEZ RIvero, Ángeles. "Fortuna di Goldoni in Spagna nel Settecento". En BRANCA,Vittorio y MANGINI, Nicola (eds.). Atti del convegno internazionale di studio goldoniani. Venecia-Roma: Istituto per la Collaborazione Culturale, 1960, pp. 315-338.

42. Fernández de Moratín, Leandro. Viage a Italia. Belén Tejerina (ed.). Madrid: Espasa-Calpe, 1988, p. 565. Pagán reconoce cuatro grandes etapas en el proceso de recepción del drama goldoniano a lo largo del XVIII: la introducción de sus piezas, que abarca el lustro 1760-1765; su desarrollo (17661777); la fase de pervivencia y triunfo, que comprende el periodo 1777-1799, y finalmente el declive tardío de este modelo teatral, que ocupa los primeros años del XIX (1800-1806), op. cit., 1997b, pp. 187-188. 
seguían imprimiéndose y representándose, como es posible deducir por demás por el Catálogo dedicado a las representaciones en Barcelona compilado por Suero Roca ${ }^{43}$, para quien en los primeros tres lustros del XIX subieron a escena no menos de 19 piezas del veneciano. Mientras en 1759 se disuelve la compañía de ópera italiana, decreciendo en Madrid por algunos años las representaciones de los espectáculos, la Ciudad Condal, que exhibía estrechos vínculos comerciales con Italia, particularmente Génova, toma su relevo: ya en 1760 es posible atestiguar la presencia de varios títulos goldonianos en la ciudad catalana (Il mercato di Malmantile, Il signor dottore, La cascina, entre otros), representados la mayor parte de ellos por la compañía del empresario Lladó.

Si en la cartelera de $\operatorname{Coe}^{44}$, que presenta no pocas lagunas, es posible localizar unas 33 piezas, procedentes de 14 obras originales del veneciano representadas en la capital, pocos años más tarde Parducci ${ }^{45}$ recopila unas 55 traducciones referidas a algo más de una veintena de títulos originales. Mucho más recientemente Suero Roca ${ }^{46}$, para el caso de Barcelona, y Pagán y Rodríguez Gómez, para toda la península, han ampliado el horizonte de la recepción del drama goldoniano: por lo que respecta el XVIII, Pagán ha actualizado los datos, habiendo localizado algo más de 110 piezas en español durante el Siglo de las Luces -unas 68 comedias y 46 dramas para música- ${ }^{47}$, confirmando el interés y notable recepción que exhibió su teatro en los escenarios españoles. Rodríguez Gómez por su parte incluye en su tesis un muy útil catálogo cronológico, referido a las representaciones en los diversos coliseos de la península a lo largo de la segunda mitad del siglo y en el que se recogen algo más de trescientas entradas, de las cuales más de un tercio remiten al último decenio del siglo ${ }^{48}$. En el Catálogo de comedias compilado por Calderone y Pagán ${ }^{49}$, de los algo más de 170 asientos referidos al teatro cómico italiano, más de 150, o sea casi un 90 \% del total, remiten a traducciones y adaptaciones españolas del autor veneciano. Esta constatación ha llevado a Pagán a sostener con razón que a lo largo del XVIII «el teatro italiano no sólo estuvo bien representado en España, sino que su máximo exponente fue el comediógrafo Goldoni con importantes títulos de su vasta producción »50.

Estos datos, sin embargo, no deberían llevarnos a sacar conclusiones absolutas: como hemos indicado en otra ocasión, «debe desestimarse un arraigo de sus

43. Suero Roca, M. ${ }^{a}$ Teresa. El teatre representat a Barcelona de 1800 a 1830. 3 vols. Barcelona: Institut del Teatre, 1989, II.

44. COE, Ada M. Catálogo bibliográfico y crítico de las comedias anunciadas en los perio'dicos de Madrid desde 1661 hasta 1819. Baltimore: John Hopkins Press, 1935.

45. PARDUCCI, Amos. Op. cit., 1941.

46. Suero Roca, M. ${ }^{a}$ Teresa. Op. cit., 1987-89, I-II.

47. Pagán, Víctor. Op. cit., 1997b, p. 485.

48. RODríguez Gómez, Inés. Op. cit., 1997, pp. 664-723

49. Calderone, Antonietta y Pagán, Víctor. Op. cit., 1997, pp. 366-402.

50. PAGÁN, Víctor. Op. cit., 1997b, p. 84. 
ideas dramáticas o una comprensión real de los componentes innovadores que ostenta el modelo teatral goldoniano en la cultura española del período" ${ }^{51}$. Con Arce, somos de la opinión de que en líneas generales el autor italiano en España en verdad «fue más traducido que valorado, al menos en su verdadero significado literario" ${ }^{52}$. Si bien es posible encontrar algunas contadas piezas que reconocen una traducción fiel al original, como El caballero del buen gusto o El amor paterno o la criada reconocida, a diferencia de Metastasio, el drama goldoniano en la España del periodo fue más un teatro adaptado y connaturalizado que traducido en el sentido literal del término. En dicha perspectiva Calderone ${ }^{53}$ enfatiza tres modalidades diversas en las que se plasmó esta presencia en los escenarios españoles: las piezas connaturalizadas -o lo que ella denomina traducciones connaturalizadas-, las connaturalizaciones indirectas y las que sufren una transcodificación de un género teatral a otro. No cabe duda de que cada autor se aproximó a la obra del veneciano según el propósito que lo animaba, por lo general a partir de los ejes temáticos que le interesaba evidenciar en las tablas, interpretándola según sus propias prioridades, el tipo de público y el nivel de cultura a los que iba dirigida la pieza.

\subsection{Goldoni: dramas jocosos y teatro musical}

La vía de penetración del comediógrafo italiano en los escenarios de España, precediendo a sus comedias, fueron sus dramas jocosos, «ya con música o transformados en zarzuelas, en español, italiano o en ediciones bilingües, en verso o prosa ya ${ }^{54}$. En las páginas precedentes se ha aludido a la configuración del mercado musical en la España de los Borbones, importado y sostenido por la familia real, primero Felipe V e Isabel de Farnesio, y sucesivamente Fernando VI, configurándose un nuevo repertorio lírico, dominado por Metastasio, que incluyó óperas serias y cómicas, intermedios y serenatas. Este mercado musical, principalmente en Madrid y Barcelona, favoreció sin duda la entrada gradual de los dramas jocosos de Goldoni, cuyos libretos adaptados por lo general al gusto nacional incrementaron el repertorio para este vigoroso drama cantado. Los vínculos estrechos entre ambas penínsulas hespéricas y la cada vez mayor presencia

51. Quinziano, Franco. Op. cit., 2008, p. 56. Por lo que atañe a la presencia de aspectos temáticos, culturales y dramáticos hispánicos en su formación artística, las presencias y las huellas en su obra son mucho más limitadas respecto a las que podemos reconocer en los dramas de Zeno, Metastasio o, en el de su gran adversario, Gozzi. Franco Meregalli asevera que los influjos del teatro áureo en el autor de La locandiera -de modo especial Lope de Vega- se hallan presentes en sus primeras piezas para luego desaparecer: Presenza della letteratura spagnola in Italia. Florencia: Sansoni, 1974, p. 46.

52. ARCE, Joaquín. Op. cit., 1981, p. 92.

53. Calderone, Antonietta. Op. cit., 1997, p. 174.

54. ARCE, Joaquín. Op. cit., 1981, p. 92. 
del italianismo musical en la corte española sin duda favorecieron la llegada de las primeras piezas goldonianas para el teatro musical.

Goldoni plasma en sus libretos una nueva poética para el teatro lírico cómico que se afirmó exitosamente en Italia a lo largo de la segunda mitad de la centuria. Su introducción en los escenarios españoles, a caballo en los años 50 y 60 del dieciocho, coincide con la consolidación y el auge del drama metastasiano. Para una cabal comprensión de la presencia y recepción de los dramas jocosos goldonianos en la península ibérica son esenciales los dos estudios de Pagán, de los que estas páginas son deudoras: su tesis doctoral, con exhaustivas indagaciones y muy útiles apéndices y el más acotado artículo dedicado al teatro cantado ${ }^{55}$. De gran relevancia para la afirmación de estos dramas fue la cada vez mayor presencia de los intermedios en los escenarios del Buen Retiro o el Sitio real de Aranjuez, con una preferencia innegable hacia la escuela napolitana (Cocchi, Corceli, Jomelli, etc.), puesto que en cierto modo estas modalidades breves anticipan la llegada del nuevo teatro cómico burgués. Respecto a los dramas jocosos representados en la península, Pagán amplía la lista de obras: si Rogers había localizado unos 36 títulos, algunos dudosos ${ }^{56}$, el investigador español reconoce en total unos 50 dramas jocosos goldonianos que, junto a los intermedios y dramas serios para música, alcanzan las 76 piezas para su representación en el teatro musical.

A finales de los años 30 del dieciocho Goldoni comienza a experimentar como libretista de intermedios ${ }^{57}$ para acompañar los melodramas de Metastasio, mientras que a partir de fines de la década de 1740 y hasta 1756 el comediógrafo establece una fructífera colaboración con el compositor Baldassare Galuppi. En 1762, con La buona figliuola maritata, el veneciano alcanza el éxito romano -y sucesivamente europeo- en el drama cantado: sus piezas con música de su nuevo colaborador, Niccoló Piccinni, acaban imponiéndose a inicios del sexto decenio con títulos como La bella veritá, Le donne vendicative y La villeggiatura, que obtienen el aplauso del público. Sus aportaciones en el campo del teatro musical son apreciables tanto en el ámbito del contenido, reduciendo las partes habladas y, por tanto, simplificando el argumento de estas piezas, así como en el plano formal, al tiempo que se amplía la variedad de formas musicales, apoyadas en la polimetría.

En una primera fase las traducciones de estos dramas, cuyas versiones en no pocas ocasiones nos han llegado anónimas, exhiben por lo general un mayor respeto a los textos originales que sus comedias, imprimiéndose en versiones bilingües italiano/español. Sucesivamente, cuando las obras comienzan a ser cantadas

55. Véanse, respectivamente, PAGÁn, Víctor. Op. cit., 1997b, y PAGán, Víctor. "Carlo Goldoni. Segunda parte: El drama jocosom. En LAFARGA, Francisco (ed.). El teatro europeo en la España del siglo XVIII. Op. cit., 1997a, pp. 183-194.

56. Rogers, Paul. Op. cit., 1940, pp. 45-68.

57. Entre 1730 y 1736 el comediógrafo veneciano compuso una docena de intermedios, mientras que entre 1756 y 1760 redactó tres farsas para música. 
en español, el panorama cambia y la praxis traductora incorpora modificaciones en estas piezas en diversos grados y planos -formales, estéticos, género, contenido, etc.-, distanciándose del texto italiano. Hacia los inicios de los años 50 se representan tempranamente en los coliseos españoles dos dramas jocosos: La maestra di buen gusto, en 1753, y un año después Il conte Caramella. Del mismo modo que sus comedias, Madrid y Barcelona -más relevante la Ciudad Condal en la primera fase- constituyen los principales ámbitos de representación, con una sucesiva, aunque menor, presencia también en las capitales de provincia (Valencia, Sevilla, Zaragoza y los teatros italianos de Cádiz y Cartagena). En Madrid, los Caños del Peral, conocido también como 'teatro italiano', constituye el ámbito privilegiado de escenificación de los drammi giocosi per musica representados por actores y cantantes de la compañía italiana de ópera. Las versiones de los libretos en español, como se ha visto también para el caso de los dramas metastasianos, se proponen respetar en los primeros años el texto original, con el fin de que el espectador pudiese comprender la historia que se representaba; ello explica que durante los primeros años, años sesenta y parte de los setenta, los libretos se imprimiesen generalmente en versiones bilingües.

Una parte relevante de estas versiones españolas permanece aún anónima: si bien se ha avanzado en estos últimos decenios en precisar la autoría de los libretos, aún queda un largo camino por recorrer. De las autorías confirmadas destaca el nombre de Cruz, autor de por lo menos unos 7 títulos goldonianos para el drama musical, entre ellos El conde Caramella (1764), La feria de Valdemoro (1764; según Leandro Moratín, autoría de Clavijo y Fajardo) y, bajo el nombre arcádico de Larisio Dianeo, El peregrino en su patria (1766). La mayoría de los comediógrafos populares mencionados al ocuparnos de las traducciones metastasianas vuelven a estar presentes como responsables de las adaptaciones del drama goldoniano para el teatro cantado. Estas versiones confirman en efecto la autoría de dramaturgos de menor rango como Bazo (La buena muchacha, 1770) y Comella (La fingida enfermera por amor; con música de Frank J. Haydn, 1797). Manuel Canfrán (El amor pastoril, zarzuela de 1765, procedente de La cascina), Francisco Enciso Castrillón (Pamela casada, 1806) y Bernardo de Guzmán (El queso de Casilda, versión lírica del sainete previamente adaptado por Moncín; de 1812 y procedente también de La cascina) son otros autores, menos conocidos, que adaptan libretos del italiano para su representación musical, como dramas jocosos para música, zarzuelas joco-serias y jocosas, sainetes líricos, etc.

Esta creciente acogida favorable de sus dramas para música coincide con la llegada al trono de Carlos III y se explica en parte por la afirmación de un nuevo gusto, asociado al aplebeyamiento de sectores de la aristocracia, que determinó en los escenarios el triunfo de lo castizo y popular. En líneas generales los dramas jocosos del veneciano vertidos al español se han revelado más próximos a los originales respecto a sus comedias. Sin embargo, estas versiones -más adaptaciones que verdaderas traducciones- para el teatro musical registran importantes modificaciones, alterando parcialmente las costumbres y los usos presentes en 
los libretos italianos, al tiempo que eliminan en ocasiones algunas alusiones de carácter político y social. Es posible reconocer asimismo omisiones por lo que atañe a algunos personajes o incluso enteras escenas; modificaciones que muchas veces se hallan en función del género al que el libreto se adecua, de la temporada y del coliseo en que se representa, así como del público al que va dirigido el espectáculo musical.

Sin duda Cruz, el mayor introductor de un buen número de obras teatrales o líricas del teatro francés e italiano, atento tanto a la práctica traductora como a la circulación de textos, desempeñó un rol central en el proceso de difusión y recepción de estos dramas goldonianos, cuyas adaptaciones en su gran mayoría fueron representadas en los escenarios madrileños en un periodo breve, apenas tres años, entre 1764 y 1767. Lafarga ha enfatizado las claves de este triunfo en las tablas españolas, al apuntar que Cruz realizó «una creativa [...] labor de transformación y adaptación, nacionalizando sus modelos, inscribiéndolos en una tradición dramática española " ${ }^{58}$. La crítica ha destacado el significativo papel desempeñado por el afamado sainetista; en tal sentido Pagán resalta la labor del madrileño en la escena nacional, al haber sabido

reelaborar numerosos textos de moda con los que producir obras suficientes para un público que no cesaba de llenar los teatros; y, al tiempo que lograba sus objetivos comerciales, modernizaba la escena española, divulgaba el mejor material europeo y definía un género netamente español, la zarzuela ${ }^{59}$.

Transitando la misma senda de Cruz, Comella vuelca su interés en ofrecer piezas del teatro extranjero para la cartelera española, especialmente para el drama musical. Aunque su obra no ofrece una gran calidad artística, significativa ha sido su aportación a la difusión del drama goldoniano. Al igual que Cruz, el catalán escribió varias zarzuelas, erigiéndose en otro significativo exponente del género, al tiempo que adaptó numerosas operetas y dramas jocosos del teatro europeo, vertiendo en traducciones libres, además de Goldoni, más de una docena de autores italianos, como Bertati, Federici, Gualzetti, Mazzolà y Da Ponte ${ }^{60}$. Por lo que respecta al drama jocoso del veneciano es autor de no menos de seis adaptaciones para el teatro musical, entre otras, La isla de la pescadora (1778), procedente de Le pescatrici; la ópera jocosa La fingida enferma por amor (1797); La isla del placer (1801), derivada también de Le pescatrici (ligeramente distinta

58. Lafarga, Francisco. «Introducción». En CruZ, Ramón de la. Sainete. Madrid: Cátedra, 1990, pp. 11-69; p. 30.

59. Pagán, Víctor. "Carlo Goldoni». En Lafarga, Francisco y Pegeneaute, Luis (eds.). Op. cit., 2004 , p. 473.

60. Ver a este respecto el perspicaz estudio de FERNÁNDEZ CABEZÓn, Rosalía. "Luciano Comella traductor del teatro italiano». En Coulon, Mireille (ed.). Le théâtre en Espagne : perméabilité du genre et traduction. Pau: Université de Pau-Éditions Covedi, 1998, pp. 147-168. 
a su primera adaptación, La isla de la pescadora) ${ }^{61}$, y el fin de fiesta El queso de Casilda (1799), que funcionó también como sainete lírico, reducción a su vez de otra adaptación en verso de Moncín de La cascina goldoniana.

La buona figliuola, uno de los mejores dramas jocosos de Goldoni, con música de Eugidio Duni y cuyo estreno en Italia había tenido lugar en Parma en 1757, en palabras de Cotarelo y Mori, constituye «uno de los éxitos teatrales más grandes que se han conocido" "2 . La recepción de este dramma giocoso constituye un eslabón significativo para comprender los cambios de gustos y las diversas modalidades de adaptación y recepción del teatro musical italiano en el XVIII. Existen diversas versiones en español de esta célebre obra, tanto en el género de la ópera bufa como así también de su adaptación al modelo de la zarzuela, con representaciones no solo en Madrid y Barcelona, sino en varios coliseos de la península, como Cádiz (1762), Sevilla $(1764,1774,1775)$ y Valencia $(1769,1777)$.

La primera representación de la pieza en España, cuyo libreto se halla redactado en italiano, tiene lugar en 1761 en Barcelona. Un año más tarde la misma compañía italiana que había estrenado el drama se desplaza a Cádiz para su representación en el coliseo de la ciudad. En esta segunda ocasión ya es posible localizar el libreto bilingüe, esencial para que los espectadores pudiesen asimilar y comprender mejor la trama y seguir el espectáculo. El autor de esta primera versión en español, La buena hija (1762), es el gaditano Juan Maruján y Cerón, quien ese mismo año vierte también otras dos obras del veneciano para el coliseo de la ciudad: El mercado de Malmantile y El boticario.

El propósito de Maruján es el de respetar, siempre que le es posible, el texto original, siendo una traducción bastante fiel. Entre las modificaciones que exhibe la traducción, la más significativa tal vez sea la ausencia del personaje Paoluccia, camarera de la Marquesa, quien desaparece de la trama. Sucesivamente, en 1765, ve la luz otra versión, La buena muchacha, adaptada al género de la zarzuela. Al reducir la trama a dos actos, su autor, Bazo, debe condensar algunas escenas y parlamentos: al igual que Maruján, elimina al personaje de Paoluccia, por lo que es posible suponer que el texto gaditano haya podido servir de base a esta adaptación zarzuelesca ${ }^{63}$. Al tener que adaptar la pieza al género de la zarzuela,

61. Distanciándose de Pagán (op. cit., 1997b, pp. 417 y 501), Angulo Egea afirma, después de un exhaustivo cotejo, que la pieza constituye en verdad una libre adaptación, no de Le pescatrici de Goldoni, sino de la ópera L'isola del piacere, libreto de Da Ponte y música de V. Martín i Soler (1799); ANGulo EgEA, María. «Traducido libremente y arreglado al teatro español»: de Carlo Goldoni a Ramón de la Cruz y Luciano Comella». Dieciocho, 2009, 32.1, p. 82. Siguiendo el Catálogo de Moratín, CALDERONE y PAGÁN atribuyen asimismo a Comella El codicioso (1802), adaptación en un acto de L'avaro, op. cit., 1997, p. 377.

62. COTARELO y Mori, Emilio. Don Ramón de la Cruz y sus obras. Ensayo biográfico y bibliográfico. Madrid: Perales y Martínez, 1899, p. 69.

63. NAVARro LÁzARO, Andrés. "Las traducciones castellanas de las óperas bufas de Carlo Goldoni: el caso de La Buona Figliuola». Res Diachronicae Virtual, 2004, 3, p. 179. 
Bazo se ve obligado a adoptar en su estrategia traductora un número no menor de modificaciones, empezando por la métrica (donde se prioriza el octosilábico), plasmando una versión que se alejaba parcialmente del texto goldoniano.

Por último, el libreto de 1769, que representó la compañía italiana de ópera ese año en el palacio de los duques de Gandía, en la ciudad de Valencia, lleva como título La buena muchacha, el mismo de la zarzuela de Bazo. Calvo Rigual, quien traza un análisis exhaustivo de este libreto anónimo, opina que el texto se revela bastante fiel al original italiano, en especial en lo que atañe al aspecto métrico, para sucesivamente emprender un iluminador estudio en clave comparada con las otras dos versiones, las de Bazo y Maruján, incorporando sugerentes consideraciones sobre las estrategias adoptadas por cada uno al volcar el texto al español $^{64}$. Ya sea que hablemos de textos traducidos respetando el texto original o libremente adaptados para ser interpretados y cantados en español o que los mismos fuesen impresos para facilitar al público la comprensión de la trama, las versiones de estas óperas jocosas constituyen un aspecto relevante que ilumina nuevos senderos, logrando ampliar el conocimiento sobre la presencia y recepción de Goldoni y su teatro musical en la España del periodo, así como una mayor comprensión sobre su proyección e influjo en las letras hispánicas.

\subsection{Goldoni: la nueva comedia de carácter y ambientación burguesa}

Como hemos observado, "aunque el drama goldoniano reconoce una discreta presencia en los últimos años del reinado fernandino, el proceso de emisión y recepción de sus dramas corresponde a una fase más tardía, siendo bien conocido el respeto y admiración que su obra despertó entre los dramaturgos de finales de siglo, vinculados a la nueva estética neoclásica, empezando por la figura señera de Leandro Moratín" ${ }^{65}$. En opinión del autor de El sí de las niñas, Goldoni constituye "el mejor poeta dramático moderno de Italia» y asevera que "ninguno de cuantos le han querido imitar o competir han sabido igualarle» ${ }^{66}$.

64. Calvo Rigual, Cesáreo. "La buona figliuola di Carlo Goldoni e le sue traduzioni spagnole». Quaderns d'Italià, 2017, 22, pp. 256-262.

65. QuinZIANO, Franco. Op. cit., 2008, p. 52.

66. FERnANDEZ DE MORATín, Leandro. Op. cit., 1988, pp. 287 y 441, respectivamente. La crítica se ha ocupado del posible influjo del comediógrafo italiano en la configuración del modelo teatral moratiniano. Sin poner en tela de juicio esta admiración hacia el dramaturgo italiano, Arce asevera que ambos eran "dos autores de temple muy distinto", sin que pudiesen aportarse pruebas irrefutables de esta influencia del autor veneciano; ARCE, Joaquín. Op. cit., 1981, p. 93. Sin negar las evidentes diferencias entre los dos dramaturgos, más recientemente se han aportado pruebas evidentes de un efectivo influjo de Goldoni sobre el comediógrafo español, que refutan las aseveraciones de Arce, como explica en un perspicaz y más reciente estudio la italianista RODRÍGUEZ GÓMEZ: "Reforma teatral e influencia del teatro de Goldoni en las obras de Moratín». En ROMERA PINTOR, Irene; BRUNI, Arnaldo y BATTISTINI, Andrea (eds.). Filologia e critica nella modernità letteraria. Studi in onore Renzo Cremante. Bolonia: CLUEB, 2012, pp. 117-134. Un panorama, algo más escueto, sobre los posibles influjos y las 
Diversos son los críticos del periodo que enjuician favorablemente el modelo dramático goldoniano, entre ellos, además de Moratín, su compatriota Napoli Signorelli, quien residió en Madrid entre 1765 y 1783, asistiendo a varias puestas en escena y adaptaciones de las obras del autor veneciano, y los más acreditados jesuitas expulsos afincados en Italia a raíz de la Pragmática carolina de 1767. El crítico partenopeo, quien -parafraseando a Voltaire- definía al veneciano como «buen pintor de la naturaleza», ponía de realce su propósito de reforma de abusos y gustos en el teatro de su país, que había erradicado el modelo de las máscaras, habiendo conferido sus piezas "tanto honor a Italia" ${ }^{67}$. Por su parte los exignacianos recalcaron las novedades del modelo teatral goldoniano, entre ellos Eximeno, Llampillas, Andrés y Arteaga, quienes enfatizaron el mérito teatral y el mensaje ético del dramaturgo italiano. Las apreciaciones de los expulsos, en líneas generales, se movieron entre el respeto, la crítica y la admiración hacia su modelo teatral.

La crítica literaria ha erigido a Goldoni en paradigma de los ideales burgueses que debía fomentar la Ilustración. En dicha perspectiva es posible aseverar que «el periodo más progresista del teatro ilustrado en España -organizado por el conde de Aranda- tiene en Goldoni uno de los mejores colaboradores, exponentes y triunfadores pese a que los textos utilizados silencien su nombre y posean frecuentemente más calidad teatral que literaria " ${ }^{68}$. Más preocupado por la recepción de sus obras en el seno del público, Goldoni hizo caso omiso de los preceptos de quienes pretendían dictar leyes universales, sin reparar en que los gustos de las naciones no son asimilables y, por otro lado, pueden variar considerablemente, por lo que concibió que era más conveniente dejar al público dueño de su propio gusto. El autor veneciano fue un hombre de teatro, más que teórico, que en ningún momento perdió de vista a su principal interlocutor: el público, para quien escribía, consciente de la necesidad de amoldarse a su gusto.

Diversos han sido los problemas que podía presentar el teatro del veneciano a la hora de volcarlo al español y adecuarlo a los escenarios de la península. Solo por indicar un ejemplo, el traductor debía decidir si respetar los nombres de las máscaras que aún se hallan presentes en algunas de sus piezas (Pantalone, Dottore, Arlecchino), manteniendo la dimensión prototípica de dichos personajes ${ }^{69}$,

concomitancias entre ambos comediógrafos, puede consultarse también en PAGÁN, Víctor. Op. cit., 1997b, pp. 139-156.

67. NAPOli Signorelli, Pietro. Storia crítica dé teatri antichi e moderni. 1. ${ }^{\mathrm{a}}$ ed. 1777. Nápoles: Orsino, 1813, X, parte I, p. 38. Entre las virtudes del veneciano que destaca el crítico napolitano, especialmente en siete comedias suyas (La putta onorata, La buona moglie, Il caffé, Il cavaliere e la dama, Pamela, L'amante militare, L'avvocato veneziano), se hallan «i quadri inimitabili dei costumi correnti, la verità espressiva dei caratteri, [e] il cuore umano disviluppato con maestria", NAPOLI Signorelli, Pietro. Op. cit., 1813, X, parte 2, p. 37.

68. PAGÁn, Víctor. Op. cit., 1997a, p. 189.

69. Chiclana, Ángel. "Algunas reflexiones sobre la traducción de Goldoni». En Lafarga, Francisco y Dengler, Roberto (eds.). Teatro y traducción. Op. cit., 1995, p. 402. 
pero despojándolos de todo exotismo y diluyendo su proximidad con el drama italiano, o bien sustituirlos y españolizarlos, pero respetando las marcas distintivas de cada uno de ellos a través de los diversos registros lingüísticos, atendiendo a las diversas marcas dialectales para su caracterización. En todo caso, más allá de las diversas alternativas que se le presentaban al traductor, el criterio mayormente transitado es el indicado por Iriarte en Los literatos en Cuaresma ${ }^{70}$, en el que prima la 'connaturalización' (o sea saber trasladar con naturalidad lo dicho de una lengua a otra), siguiendo los preceptos de la estética neoclásica, respetuosa de la máxima horaciana del prodesse et delectare.

Una parte significativa de los comediógrafos españoles percibió la carga cómica y al mismo tiempo el realismo de estas piezas, componentes que se adecuaban al propósito de enseñar deleitando y deleitar enseñando y en el que el teatro se erigía en instrumento de educación y reforma social y moral. Muchos de los temas que configuran el universo goldoniano se aproximan a cuestiones y preocupaciones que caracterizaban la sociedad española del tiempo. La obsesión por el rango social, la mala educación de los hijos, las uniones matrimoniales desiguales -por condición social o diferencia de edad-, la vanidad y la ostentación, la crítica a la nobleza ociosa y corrupta, la educación de la mujer, el cortejo y el chischibeo, los abusos de los padres, la avaricia y la mentira compulsivas, la exaltación de la virtud burguesa, etc., son algunos de los temas "públicos» que ponen de realce las comedias del veneciano. Estos ejes temáticos, en primer lugar, la denuncia de los matrimonios desiguales, causa de la desintegración de la familia como institución, y patrimonio por demás del pensamiento ilustrado y burgués, suscitan el interés de los comediógrafos españoles, con una clara predilección hacia sus comedias de carácter y de ambientación burguesa.

Muchos de estos ejes temáticos, de innegables implicaciones morales, sociales y éticas, así como sus propósitos de reforma, fueron percibidos por los autores españoles como próximos a la realidad española y a sus propias preocupaciones. No sorprende, pues, que, con alguna contada excepción, aquellos no hayan demostrado ningún interés hacia las comedias de ambiente veneciano, asociadas directamente a las problemáticas y costumbres de la ciudad lagunar, distantes de la realidad española y en la que los personajes goldonianos priorizaban el dialecto en sus diálogos. Por su parte han sido solo dos las comedias de ambiente exótico o extranjero que acabaron volcándose al español: La esposa persiana y La bella guayanesa, adaptación lograda, esta última, de Fermín de Laviano, procedente de La bella selvaggia. Si en la pieza italiana se plasma una virtuosa condena del proceso de conquista del continente americano, como instrumento de explotación y de acumulación de riquezas, la versión española, por el contrario, traza una clara

70. IrIARTe, Tomás de. Op. cit., 2005, pp. 201-202. 
justificación del proceso de conquista y evangelización española, con lo que se aleja de la pieza original ${ }^{71}$.

De las numerosas comedias que subieron a los escenarios fueron La posadera feliz, los Caprichos de amor y celos, La mujer prudente, Un curioso accidente y, en especial, El criado de dos amos, las que obtuvieron el mayor aplauso del público, registrando varias funciones en los últimos decenios de la centuria. Con la excepción del renombrado sainetista y traductor experto Ramón de la Cruz, al que se le atribuyen la adaptación de las dos partes de Pamela-Pamela nubile; Pamela maritata- y no menos de 7 dramas jocosos, la amplia mayoría de los que se aproximaron a sus piezas para volcarlas al español pertenecen al mundo teatral de menor rango, autores de segundo orden conformado por comediógrafos, apuntadores y comediantes, en general acusados por los neoclásicos de haber introducido el mal gusto en los escenarios y que también, como se ha visto, se ocuparon de varias de sus piezas jocosas para el drama musical. Se trata de comediógrafos u hombres vinculados al mundo teatral, empeñados en traducir obras extranjeras para dar respuesta a la cada vez mayor demanda de nuevos títulos en la cartelera teatral, y que al mismo tiempo perciben las potencialidades cómicas y el virtuoso caudal de temas que exhiben las piezas del veneciano.

Comella, Ignacio González del Castillo, Valladares y Sotomayor, Botti y Bazo, el apuntador Moncín y Concha, con cinco o más piezas traducidas, y Laviano y López Sedano, con tres como mínimo, son algunos de los autores que exhiben una clara afición hacia su teatro. Estas versiones exhiben en general no pocas modificaciones, mutilaciones y deturpaciones respecto a los textos originales, algunas más felizmente logradas que otras, constituyendo ejemplos significativos de connaturalización en el proceso de traducción y adaptación. Ello no significa que no sea posible reconocer la existencia de algunas traducciones fieles al texto original, como por ejemplo El caballero de espíritu (Il cavaliere di spirito) o Curar los males de amor es la física mayor (Il medico olandese). Sin embargo, las versiones literales no constituyen los ejemplos más representativos al hablar de las comedias goldonianas, al imponerse la adaptación, la reescritura y recreación como prácticas mayormente consolidadas.

Concha, verdadero hombre de teatro (actor, empresario teatral, adaptador y autor), del que se conocen pocos datos biográficos, adaptó no menos de 8 piezas del veneciano, entre las que se recuerdan El hablador (1775), La nuera sagaz (1776), El criado de dos amos (1777, ¿1787?) y La viuda sutil (1778). Según Calderone $^{72}$, además de ser el autor de la adaptación en prosa de la primera versión de

71. Véase CALDERONE, Antonietta. "De La bella selvaggia a La bella guayanesa: Carlo Goldoni e la commedia di tema americano in Spagna». En CARACCIOLO, Angela (ed.). Il letterato tra miti e realtà del Nuovo Mondo: Venezia, il mondo iberico e l'Italia. Roma: Bulzoni, 1996, pp. 117-129.

72. Calderone, Antonietta. "Gli adattamenti settecenteschi in Spagna di Il servitore di due padroni». En DE CESARE, Giovanni (ed.). La fiesta teatral hispánica. Nápoles: Istituto Universitario Orientale, 1995, pp. 326-327. 
El criado de dos amos, de 1787 (Il servitore di due padroni), Concha sería también, con toda probabilidad, el traductor de la segunda versión en versos octosilábicos, redactada y representada diez años más tarde. El autor evidenció su admiración hacia Goldoni, pudiéndose reconocer además en algunas de sus piezas el innegable influjo del italiano, como es posible verificar en Más sabe el loco en su casa que el cuerdo en la ajena y el natural vizcaino (1791), perteneciente al género de la comedia de figurón, aunque muy próxima a la comedia de costumbres y caracteres típicamente burguesa que brilló en los escenarios con Goldoni.

Las dos adaptaciones de El criado de dos amos constituyen un ejemplo emblemático de los complejos y sinuosos senderos por los que transitó el teatro goldoniano en la España del XVIII. Los mecanismos e itinerarios de la recepción española del comediógrafo de Venecia presentan, en efecto, no pocas dificultades a la hora de explorar su estudio, puesto que es muy común reconocer tres -o másadaptaciones en español, procedentes del mismo texto original, muchas veces incluso con el mismo título, aunque constituyan versiones distintas, conviviendo en un mismo periodo en los escenarios. Abundan varios ejemplos de ello, como sucede con las diversas adaptaciones dieciochescas de una de sus piezas más célebres, La locandiera (1753): La posadera y el enemigo de las mujeres (1798), de autor anónimo, El enemigo de las mujeres o la posadera (1779) y La posadera feliz o el enemigo de las mujeres (1799), ambas de López de Sedano ${ }^{73}$.

No han faltado asimismo las confusiones, debido a la similitud de títulos o en presencia de dos -o más- obras con títulos diversos, pero procedentes de una misma pieza, en razón de la libertad con la que los adaptadores acometían su labor. Ejemplo de esto último lo ofrecen las dos traducciones de L'osteria della posta que realizan Valladares y Sotomayor (La posada feliz, 1780) y Moncín ( $E l$ feliz encuentro, 1792), si bien, como advierte Calderone, ambas «mantienen inalterados tanto el tema como las relativas argumentaciones ${ }^{74}$ referidas a las uniones matrimoniales establecidas por interés u otros fines, pero que excluían el amor recíproco entre los novios.

Es posible identificar asimismo versiones en español con títulos muy similares que se intercalan en la representación en los escenarios a lo largo de un determinado arco temporal, y que pueden generar no poca confusión entre los lectores y la crítica. A modo de ejemplo, Il geloso avaro (1753) reconoce, al menos, 4 adaptaciones distintas, cada una de ellas con un título diverso, aunque muy similar: La mujer prudente y el usurero celoso, en prosa, de Concha (s. a.); El celoso avaro, en verso, acometida por Bazo en 1773; El usurero celoso y la prudente mujer, de

73. De gran utilidad resulta la exhaustiva lista de piezas goldonianas en España, desde el XVIII hasta nuestros días, compilada por PAGÁn en su tesis doctoral (op. cit., 1997b, pp. 293-381) y la no menos útil de RODRíGuEz GómEz, referida a la segunda mitad de la centuria, en sus apéndices II y III (op. cit., 1997, pp. 664-768), que despejan no pocas dudas y falsas atribuciones hasta nuestros días.

74. Calderone, Antonietta. Op. cit., 1997, p. 158. 
Valladares (1777), también en verso, y una reducción al género del sainete, realizada por el autor de tonadillas José Palomino, que vio la luz en 1799 con el título El avaro celoso. Por su parte, a inicios del siglo XIX es posible localizar otras dos piezas, El hombre convencido a la razón o La mujer prudente (1810) y La mujer prudente (1815), ambas en verso y acometidas por Manuel Santos Cipriano, pero que, a pesar de la similitud de sus títulos con las precedentes, no guardan ningún tipo de relación, puesto que constituyen libres adaptaciones de otra comedia del veneciano, La moglie saggia.

La sinonimia o semejanza de títulos en la selva de piezas goldonianas, así como la proliferación de adaptaciones con diversos títulos, aunque referidas a una misma pieza original, en algunos casos con más de una versión en verso o en prosa, han constituido un verdadero laberinto para la crítica. No extraña, pues, que no hayan sido pocos los errores cometidos en la ardua labor de identificar las diversas versiones, así como las falsas atribuciones. En los últimos decenios, sobre todo a partir de los años 60 del siglo pasado, se han ido despejando la mayoría de las dudas a este respecto. Por lo general los casos que reconocen una doble traducción exhiben una primera versión en prosa y sucesivamente una segunda en verso, como el recién citado caso de La posadera o el enemigo de las mujeres (en prosa: anónima de 1798; en verso: López de Sedano, de 1799). Sin embargo, no es extraño encontrar, aunque en menor proporción, el caso inverso: a saber, una primera trasposición en verso, como Las cuatro naciones o la viuda sutil, acometida por Valladares y Sotomayor (1778), y luego una segunda en prosa, La viuda sutil, de Concha (1788), ambas procedentes de La vedova scaltra.

Estos procesos de doble traducción en general corroboran una clara interdependencia de las dos versiones españolas, siendo por lo general la segunda traducción o adaptación una trasposición de la primera -y directa- connaturalización, aunque a veces estos itinerarios pueden exhibir itinerarios más complejos y sinuosos. Un ejemplo de ello nos lo proporciona la aludida pieza El amo de dos criados: aquí es posible reconocer también una primera adaptación en prosa, acometida por Concha en 1777, que españoliza parcialmente nombres, costumbres y nombres, y una sucesiva versión, en verso, editada diez años más tarde, de autor anónimo, que presenta una mayor correspondencia con aspectos tradicionales propios de la escena española y que parece no proceder directamente de la adaptación de Concha, sino de un sainete posterior a la primera connaturalización: Dos piezas de un pensamiento y un criado ser dos a un tiempo, de Sebastián Vázquez (1777), quien a su vez había realizado una reducción de la adaptación directa de Concha del mismo año ${ }^{75}$. El sainete, con su mayor carga cómica, expresiones populares y lenguaje entremesil, significativamente aquí texto 'intermediario' en el proceso de trasposición que plasma el pasaje de la primera versión en prosa a

75. Véase a este respecto el iluminador estudio de CALDERONE, Antonietta. Op.cit., 1995, pp. 334-343. 
la sucesiva versificación en romance octosilábico, asimilando registros propios del habla popular, al tiempo que incorpora una mayor carga de comicidad que roza lo grotesco.

Bazo, traductor también de Metastasio, vuelca al español no menos de 5 comedias del veneciano: La criada más leal (1763), El caballero y la dama (1765), El celoso avaro (1773), El pródigo (1772) y La buena muchacha (1765), algunas de las cuales han sido objeto de estudio de Fernández Cabezón ${ }^{76}$. De ellas El caballero y la dama es la que ha obtenido mayor repercusión, pues logra mantenerse presente en cartelera casi 5 lustros, desde que en 1765 se estrena hasta 1789, reponiéndose casi todas las temporadas. Por su parte El pródigo (Il prodigo) y El celoso avaro (Il geloso avaro) se hallan orientadas a satirizar determinados tipos sociales y a poner de realce en clave crítica algunos comportamientos éticos en la sociedad, fuertemente reprobables.

Una de las temáticas mayormente presente en estas piezas se refiere a la cuestión de los matrimonios desiguales, abogando Bazo por uniones de una misma condición social y condenando al mismo tiempo, como Moratín y una amplia lista de escritores, las nupcias entre cónyuges de diversa edad (hombre viejo/dama joven). Ejemplo de ello son sus traducciones de La buena muchacha (La buona figliuola) y La criada más leal (La serva amorosa), bastante fiel al original. Sin embargo, será la adaptación de Fermín del Rey de esta última comedia, con el título La buena criada (1778), en romance octosilábico y más conseguida respecto a la versión precedente, la que logrará imponerse en los escenarios madrileños, con varias representaciones a lo largo del último decenio de la centuria ${ }^{77}$. La trasposición en versos de la pieza se adecua perfectamente a los propósitos que debían respetar las comedias neoclásicas, erigiéndose Rey en modelo de buen traductor, a tal punto que el censor de la pieza, Díaz González, al aprobar la obra, afirma significativamente que el traductor "no solo ha expresado bien el original, sino que le ha mejorado de manera que no parece traducción ${ }^{78}$, con lo que superaba al modelo original del que procedía.

Al igual que en el caso de las versiones de Il servitore di due padroni, comentadas precedentemente, no constituye una tarea fácil poder distinguir las interconexiones y diferencias entre ambas versiones de La locandiera, la anónima y la versificada por López de Sedano, entre sí y con la pieza original, teniendo en cuenta por demás que ambas traducciones se alternaron en los escenarios entre 1777 y 1798. En su estudio Calderone ${ }^{79}$ explora con perspicacia las relaciones intertextuales y las interconexiones directas y cruzadas entre las distintas versiones

76. FERnÁNDEZ CABEzón, Rosalía. "Antonio Bazo traductor del teatro italiano". En VACCARI, Debora (ed.). Rumbo del Hispanismo en el umbral del cincuentenario de la AIH. Roma: Bagatto, 2012, IV, pp. 292-297.

77. Andioc, Renè y Coulon, Mirelle. Op. cit., 1996, p. 642.

78. Cit. en Calderone, Antonietta. Op. cit., 1993, p. 87; el subrayado es mío.

79. Calderone, Antonietta. Op. cit., 1984, pp. 48-50. 
de la afamada comedia, al tiempo que fija una tipología de grados diversos respecto a la fidelidad ideológica o lingüística de las mismas.

Comella, comediógrafo y adaptador, célebre por sus portentosos dramas heroicos, vuelca también al español varias piezas goldonianas, en especial adaptando varios libretos para el teatro musical. En el género de la comedia vertió en prosa solo El indolente (o El Poltrón, 1792), procedente de Il tutore (1752); adaptación bastante libre, puesto que se trata de una reducción en dos actos, en la que se abrevian algunos parlamentos y escenas. Mucho más provechosa, como se ha visto, es su labor de adaptación y arreglo de dramas jocosos para el teatro musical, entre los que destaca El buen médico o la fingida enferma por amor (1797), versión en prosa de La finta ammalata o Lo speziale, con música de Haydn.

Por último, aunque en mucho menor medida que su adaptación al modelo de la zarzuela o las comedias heroicas, algunas piezas del autor veneciano fueron vertidas al español ajustándose a la fórmula teatral del sainete, con todo lo que ello implicó en las estrategias de selección, modificación y principalmente, debido a su brevedad, eliminación de personajes, situaciones, diálogos, escenas, etc. Además de la ya mencionada adaptación de Vázquez en dos actos, es posible reconocer al menos otros sainetes de clara derivación goldoniana, sobre los que, una vez más, se ha detenido Calderone en un apreciable estudio ${ }^{80}$ : Un avaro celoso, en el que el anónimo autor reduce las partes más sobresalientes de la comedia El usurero celoso y la mujer prudente (1777), procedente a su vez de L'avaro geloso, adaptada por Valladares; Las chismosas (1791), de Moncín, adaptación de I pettegolezzi delle donne, y el más tardío, y único que llegó a publicarse en aquellos años, La casa nueva (1812, La casa nova), sainete en verso de González del Castillo.

\section{Otras traducciones: NAPOli SignORELli, MAFFeI, BetTinelli}

Es posible reconocer la presencia en las carteleras de otros autores italianos, cuyas piezas son volcadas al español, aunque esta recepción desde ya se revela muy inferior, casi marginal, respecto al dominio incontrastable que ejercieron Metastasio y Goldoni. Uno de los comediógrafos que mayor atención prestó al drama italiano como fuente para la renovación del repertorio es Comella, quien vierte al español diversos libretos para el teatro musical ${ }^{81}$. El comediógrafo catalán dota a la cartelera española de varios títulos procedentes del drama italiano contemporáneo: además de Goldoni, traslada al español, entre otros textos, algunas comedias de G. A. Gualzetti (Los amores de conde Cominges, 1796) y C. Federici (Los falsos hombres de bien, 1790). Asimismo acomete también varias adaptaciones de

80. CALDERONE, Antonietta. "Quattro sainetes "goldoniani"». En GARELli, Patrizia y MARChETTI, Giovanni (eds.). 'Un hombre de bien'. Saggi di lingue e letterature iberiche in onore di Rinaldo Froldi. Alessandria: ed. dell'Orso, 2004, I, pp. 131-146.

81. Fernández Cabezón. Rosalía. Op. cit., 1998. 
libretos italianos para el teatro musical, vertiendo, entre otras, las óperas bufas en dos actos La escuela de los celosos (C. Mazzolà; música de A. Salieri), El matrimonio secreto (G. Bertati; música de Cimarrosa), la ópera jocosa en dos actos La cifra (L. de Ponte; música de A. Salieri) y El codicioso (L'avaro; G. Bertati; música de P. Anfossi).

En el campo del teatro cómico, donde la estela de Goldoni reina incontrastable, es posible registrar solo muy contadas traducciones de otros autores italianos. Además de algunas versiones de Chiari, autor de unas 60 comedias, destaca La Faustina (1775), comedia sentimental del dramaturgo y crítico partenopeo Napoli Signorelli, quien residió en Madrid entre 1765 y 1783, donde estrechó sólidos vínculos de amistad literaria con el círculo neoclásico de Nicolás Moratín. La pieza, "traducida con bastante fidelidad" al original, según recuerda el mismo autor napolitano ${ }^{82}$, es volcada al español en 1785 por Fermín del Rey, representándose al año siguiente en el coliseo del Príncipe, donde obtuvo un éxito de público nada desdeñable.

Aunque la tragedia clasicista francesa es la que domina las carteleras españolas del setecientos, erigida en modelo a imitar, es posible reconocer un puñado de traducciones o reescrituras de piezas trágicas italianas (Maffei, Bettinelli, Chiari, Albergati), concebidas también como modelos y fuentes de inspiración. La Merope, de Scipione Maffei, es un ejemplo de ello. Su autor, prestigioso dramaturgo, filósofo y erudito, de quien Luzán vierte en romance octosilábico su comedia Le ceremonie, es una personalidad destacada del Settecento italiano, por los variados intereses científicos y culturales que cultivó.

Algunas traducciones de su Merope al español fueron confundidas por algunos críticos con las de la tragedia de Voltaire del mismo título (Mérope, 1744), cuyo modelo se distancia del que plasmó el autor italiano, con quien por demás polemizó. Traducida a varias lenguas europeas, reconoce dos traducciones al español: la primera de 1753, a cargo del mallorquín Luis Foco $^{83}$, mientras en 1801, como anota Herrera Navarro ${ }^{84}$, el canario Viera y Clavijo, erudito neoclásico y traductor de varias piezas del francés, acomete una nueva traducción que no llega a imprimirse y cuyo manuscrito se halla depositado en los fondos de la Universidad de La Laguna, disponible en la red (www.europeana.eu). Foco respeta en lo esencial el texto original, siguiendo su trama y estructura, aunque opta por verter los endecasílabos sueltos en prosa, más apropiada y natural en su opinión, como para la mayoría de los neoclásicos, para la redacción de las tragedias.

82. Napoli SignORelli, Pietro. Op. cit., 1813, X, pp. 233-234.

83. Garcías Esterlich, Domingo. "Luis Foco (1699-1767) y la defensa del teatro neoclásico». Bolletí de la Societat Arqueològica Lulliana:Revista d'Estudis Històrics, 1998, 54, pp. 243-260.

84. Herrera NAVARro, Jerónimo. Catálogo de autores teatrales del siglo XVIII. Madrid: Fundación Universitaria Española, 1993, p. 475. 
Por último, del mantuano Severio Bettinelli, célebre por sus polémicas sobre el estado de la literatura y cultura españolas, se ha volcado en español su tragedia en 5 actos Serse, re di Persia (1764), que obtuvo una aceptable repercusión en los escenarios españoles. El autor de la adaptación, intitulada Xerxes, es el abogado Miguel A. García Asensio, quien vierte la pieza en 1801. García Asensio en su Prólogo explica su visión sobre la labor traductora emprendida: «El traductor debe expresarlo todo en la suya [su lengua], o ya con las mismas expresiones y voces, si las dos lenguas tuviesen alguna afinidad ${ }^{85}$, advirtiendo que en su empeño ha procurado seguir fielmente el texto original.

\section{CONCLUSIÓN}

El auge de las traducciones, en las que destacan las estelas de Metastasio y Goldoni, implicó una ampliación de los horizontes culturales y una contribución significativa al proceso de circulación e intercambio de ideas, al tiempo que los traductores acabaron erigiéndose en privilegiados intermediarios entre ambas penínsulas en contacto. La traducción de obras teatrales italianas, proceso que debe ser concebido en el marco del vasto entramado de presencias, influjos y recepciones entre ambas penínsulas a lo largo de la centuria, contribuyó decididamente a afianzar gustos y tendencias estéticas, al aproximar textos y autores de la península al lector español, superando tópicos y anclados prejuicios entre ambas culturas, al tiempo que configuró un ámbito de saludable confrontación. Significativa fue asimismo la aportación del caudal de textos teatrales italianos para la formación de un renovado repertorio y en la definición de modelos, algunos de los cuales lograron afirmarse en las carteleras españolas con notable éxito, adecuándose las diversas versiones a un sinfín de géneros y subgéneros dramáticos en sus diversas etapas (melodrama, ópera jocosa, zarzuela, intermedios, zarzuelas, comedias heroicas, sainetes, etc.).

$\mathrm{Al}$ aludir al vasto repertorio de Metastasio y Goldoni, Lafarga precisa que «la investigación se ha visto complicada por la diversidad tipológica que adoptaron las versiones, a veces con títulos dispares ${ }^{86}$. Abundan los ejemplos de ello; para circunscribirnos al autor romano, y a modo de ejemplo, han sido diversas las traducciones y adaptaciones que registra su Demofoonte, libreto que, como drama en música, sube a los escenarios en el coliseo de Caños del Peral en 1738. Sucesivamente, como comedia nueva, es adaptada por Ramiro Díaz Sigiro; más tarde se adecua al género de la zarzuela bajo el título de La más infeliz fortuna y el más venturoso amor, adaptación de Manuel D. Delgado, para volvernos a encontrar nuevamente en 1791 con una nueva versión española del melodrama, traducido

85. Cit. en García Garrosa, M. ${ }^{a}$ Jesús y LAFARGA, Francisco. El discurso sobre la traducción en la España del siglo XVIII. Estudio y antología. Kassel: Reichenberger, 2004, p. 347.

86. Lafarga, Francisco. «Introducción». En Lafarga, Francisco (ed.). Op. cit., 1997, p. 12. 
por el dramaturgo García Malo, ahora bajo el título de El inocente usurpador, sin olvidar la presencia de otra versión española, que registra Garelli (nota), sin fecha de redacción y que no ha sido editada aún, permaneciendo manuscrita bajo el nombre Demofoonte, rey de Tracia.

Como se desprende de este excursus, han sido diversas las estrategias y variados los modos en que los autores españoles se aproximaron al drama italiano con el propósito de configurar un nuevo repertorio teatral, pudiéndose reconocer, en especial en los inicios de la introducción del drama metastasiano, una mayor presencia de versiones fieles, en general respetuosas de los originales, publicadas en versiones bilingües. A medida que avanza la centuria fue acentuándose la práctica de una mayor libertad con una creciente presencia de libres adaptaciones, verdaderas recreaciones personales, mientras que en los últimos lustros del siglo se imponen estos procesos de libre adaptación de las piezas italianas, amoldadas al gusto nacional y acomodadas a otros géneros dramáticos (como la zarzuela, la comedia heroica o el sainete). Emblemáticos en dicha perspectiva han sido los diversos itinerarios por los que transitaron las versiones españolas del drama de Metastasio para el teatro musical en los años centrales de la centuria, promoviendo el triunfo del italianismo musical. Múltiples han sido también los senderos explorados por los traductores españoles respecto a algunos dramas jocosos de Goldoni, pero en especial -y de modo más acusado-, al acometerse la traducción de varias de sus comedias, algunas de cuyas versiones -en su proceso de adaptación a la escena española- llegaron a exhibir modalidades e itinerarios enrevesados y sinuosos, reflejando varios estadios de interconexión e interdependencia, ya sea directa o indirecta, respecto a la obra original de la que han bebido, pero también respecto a dos o más versiones distintas procedentes de un mismo texto goldoniano.

\section{Bibliografía}

ANDIOC, René y Coulon, Meirelle. Cartelera teatral madrileña del siglo XVIII (1708-1808). 1. ${ }^{a}$ ed. Toulouse: Press Universitaries du Mirail, 1996. 2. ${ }^{a}$ ed. corr. y aum. (Madrid: Fundacio'n Universitaria Española, 2008).

Angulo EgEA, María. "Traducido libremente y arreglado al teatro español': de Carlo Goldoni a Ramón de la Cruz y Luciano Comella». Dieciocho, 2009, 32.1, pp. 75-100.

ARCE, Joaquín. La poesía del siglo ilustrado. Madrid: Alhambra, 1981.

BALDissera, Andrea. «Metastasio en España, entre traducciones y refundiciones». Boletín de la Biblioteca de Menéndez Pelayo, 2007, LXXXIII, pp. 153-175.

Buiguès, Jean Marc. «Les traductions dans l'Espagne des Lumiéres: langues, rythmes et contenus». Bulletin Hispanique, 2002, 1, pp. 101-119.

CALderone, Antonietta. «Da Mirandolina a Liseta (su La locandiera in Spagna)». Letterature, 1984, 7, pp. 28-73. 
FRANCO QUINZIANO

FIDELIDAD, LIBRE ADAPTACIÓN, RECREACIÓN. ITINERARIOS DEL TEATRO ITALIANO EN LA ESPAÑA...

CALDERONE, Antonietta. "La buena criada e La serva amorosa: una traduzione migliore dell'originale?». En De místicos y de mágicos, clásicos y románticos. Homenaje a Ermanno Caldera. Messina: Armando Siciliano, 1993, pp. 87-109.

CAlderone, Antonietta. "Gli adattamenti settecenteschi in Spagna di Il servitore di due padroni». En De Cesare, Giuseppe (ed.). La fiesta teatral hispánica. Nápoles: Istituto Universitario Orientale, 1995, pp. 317-343.

CALDERONE, Antonietta. "De La bella selvaggia a La bella guayanesa: Carlo Goldoni e la commedia di tema americano in Spagna». En Caracciolo, Angela (ed.). Il letterato tra miti e realtà del Nuovo Mondo: Venezia, il mondo iberico e l'Italia. Roma: Bulzoni, 1996, pp. 117-129.

Calderone, Antonietta. "Carlo Goldoni: la comedia». En Lafarga, Francisco (ed.). El teatro europeo en la España del siglo XVIII. Lleida: Universitat de Lleida, 1997, pp. 139-181.

CAlderone, Antonietta. "Quattro sainetes "goldoniani"». En Garelli, Patrizia y MarchetTi, Giovanni (eds.). 'Un hombre de bien'. Saggi di lingue e letterature iberiche in onore di Rinaldo Froldi. Alessandria: Edizioni dell'Orso, 2004, I, pp. 131-146.

CALderone, Antonietta y PAGÁn, Víctor. "Traducciones de comedias italianas». En LAFARga, Francisco (ed.). El teatro europeo en la España del siglo XVIII. Lleida: Universitat de Lleida, 1997, pp. 139-181.

CALvo Rigual, Cesáreo. "La buona figliuola di Carlo Goldoni e le sue traduzioni spagnole». Quaderns d'Italià, 2017, 22, pp. 241-262.

Chaves Montoya, Teresa y De la Flor, Fernando. «Teatro musical». En CARnero, Guillermo (ed.). Historia de la literatura española. Siglo XVIII (I). Madrid: Espasa-Calpe, 1995, pp. 372-399.

ChIClanA, Ángel. "Algunas reflexiones sobre la traducción de Goldoni». En Lafarga, Francisco y Dengler, Roberto (eds.). Teatro y traducción. Barcelona: Universitat Pompeu Fabra, 1995, pp. 399-404.

CoE, Ada M. Catálogo bibliográfico y crítico de las comedias anunciadas en los periódicos de Madrid desde 1661 hasta 1819. Baltimore: John Hopkins Press, 1935.

COTARELO y MORI, Emilio. Don Ramón de la Cruz y sus obras. Ensayo biográfico y bibliográfico. Madrid: Perales y Martínez, 1899.

FABBRI, Maurizio. "Il ruolo del teatro nelle relazioni culturali tra Italia e Spagna nel secolo XVIII». En Il teatro dimenticato. Note su testi minori del Settecento spagnolo. Rimini: Panozzo, 2016, pp. 101-109.

Feijoo, Benito J. «El deleyte de la Música». En Cartas curiosas y eruditas. Madrid: A. Pérez de Soto, 1765, vol. IV, carta I, pp. 1-37.

FERnÁNDEZ CABEZón, Rosalía. «Influencia de Metastasio en la comedia heroica de Gaspar Zavala y Zamora». Anuario de Estudios Filológicos, 1989, 12, pp. 81-87.

FERnÁNDEZ CABEZón, Rosalía. "Luciano Comella traductor del teatro italiano». En Coulon, Mireille (ed.). Le théâtre en Espagne: perméabilité du genre et traduction. Pau: Université de Pau-Éditions Covedi, 1998, pp. 147-168.

FERnÁndez CABEzón, Rosalía. "Antonio Bazo traductor del teatro italiano". En VACCARI, Debora (ed.). Rumbo del Hispanismo en el umbral del cincuentenario de la AIH. Roma: Bagatto, 2012, IV, pp. 287-297.

FERnÁNDEZ FERnÁNDEZ, Olga. "La clemencia de Tito de Metastasio en la traducción de Luzán y la visión de la ópera a través de los neoclásicos españoles del siglo XVIII». Dieciocho, 2001, 24. 2, pp. 217-244. 
García Garrosa, M. ${ }^{a}$ Jesús y Lafarga, Francisco. El discurso sobre la traducción en la España del siglo XVIII. Estudio y antología. Kassel: Reichenberger, 2004.

García Garrosa, M. ${ }^{a}$ Jesús y Lafarga, Francisco. "La historia de la traducción en España en el siglo XVIII. En SABIO PINILla, José A. (ed.). La traducción en la época ilustrada (panorámicas de la traducción en el siglo XVIII). Granada: Comares, 2009, pp. 27-80.

GARCíA-HurTADO, Manuel. «La traducción en España, 1750-1808: cuantificación y lenguas en contactom. En LAFARGa, Francisco (ed.). La traducción en España (1750-1830): lengua, literatura, cultura. Lleida: Universitat Lleida, 1999, pp. 35-43.

Garcías Esterlich, Domingo. "Luis Foco (1699-1767) y la defensa del teatro neoclásico». Bolletí de la Societat Arqueològica Lulliana. Revista d'Estudis Històrics, 1998, 54, pp. 243-260.

Garelli, Patrizia. "Dos adaptaciones de Didone abbandonata de Pietro Metastasio en el teatro español de la segunda mitad del siglo XVIII». En Lafarga, Francisco y Dengler, Roberto (eds.). Teatro y traducción. Barcelona: Universitat Pompeu Fabra, 1995, pp. 95-108.

GARELLI, Patrizia. "Ramón de la Cruz, adaptador de melodramas metastasianos». En SAla VAllDaURA, Josep M. ${ }^{a}$ (ed.). El teatro europeo del siglo XVIII. Lleida: Universitat de Lleida, 1996, II, pp. 447-473.

GARELLI, Patrizia. «Metastasio y el melodrama italiano». En LAFARGA, Francisco (ed.). El teatro europeo en la España del siglo XVIII. Lleida: Universitat de Lleida, 1997a, pp. 127-138.

GarelLi, Patrizia. «Traducciones de tragedias italianas». En LAFARGA, Francisco (ed.). El teatro europeo en la España del siglo XVIII. Lleida: Universitat de Lleida, 1997b, pp. 325-363.

Garelli, Patrizia. «Metastasio, Pietro». En Lafarga, Francisco y Pegenaute, Luis (eds.). Diccionario Histórico de la Traducción en España. Madrid: Gredos, 2009, pp. 783-785. Web: http://phte.upf.edu/dhte/italiano/metastasio-pietro

Herrera NaVArRo, Jerónimo. Catálogo de autores teatrales del siglo XVIII. Madrid: Fundación Universitaria Española, 1993.

Iriarte, Tomás de. Los literatos en Cuaresma. 1. ${ }^{a}$ ed. 1773. Emilio Martínez Mata y Jesús Pérez-Magallón (eds.). Madrid: Nueva Biblioteca, 2005.

LAFarga, Francisco. "Traducción e historia del teatro: el siglo XVIII". Anales de Literatura Española, 1986-87, 5, pp. 219-230.

Lafarga, Francisco. "Introducción». En Cruz, Ramón de la. Sainete. Madrid: Cátedra, 1990, pp. 11-69.

LAFARGA, Francisco. "Introducción» y "La comedia francesa». En LAFARGA, Francisco (ed.). $E l$ teatro europeo en la España del siglo XVIII. Lleida: Universitat de Lleida, 1997, pp. 9-12 y $87-104$.

LAFARGA, Francisco. «Hacia una historia de la traducción en España (1750-1830)». En LAFARGA, Francisco (ed.). La traducción en España (1750-1830): lengua, literatura, cultura. Lleida: Universitat de Lleida, 1999, pp. 11-31.

LAfarga, Francisco. "El siglo XVIII, de la Ilustración al Romanticismo". En Lafarga, Francisco y Pegenaute, Luis (eds.). Historia de la traducción en España. Salamanca: Ambos Mundos, 2004, pp. 209-319.

LAFARGA, Francisco. "La traducción de piezas extranjeras como vía hacia la modernidad en el teatro español del siglo XVIII». MonTI, 2013, 5, pp. 299-324.

LASA ÁLVAREZ, Begoña. «Los traductores franceses como intermediarios culturales durante el siglo XVIII y su vigencia en la actualidad». En LAfarGa, Francisco; LLORCA, Ángeles y 
FIDELIDAD, LIBRE ADAPTACIÓN, RECREACIÓN. ITINERARIOS DEL TEATRO ITALIANO EN LA ESPAÑA..

SIRVENT, Ángeles (eds.). Le XVIIIe siècle aujourd'hui: présences, lectures et réécritures. París: Le Manuscrit, 2016, pp. 273-285.

LEZA, José M. ${ }^{a}$. «Metastasio on the Spanish stage: Operatic adaptations in the public theatres of Madrid in the 1730s". Early Music, 1998, XXVI. 4, pp. 623-631.

MariutTi de SáNChez Rivero, Ángeles. «Fortuna di Goldoni in Spagna nel Settecento». En Branca, Vittoria y Mangini, Nicola (eds.). Atti del convegno internazionale di studio goldoniani. Venecia-Roma: Istituto per la Collaborazione Culturale, 1960, pp. 315-338.

Martín Puente, Cristina. "Las obras sobre la historia de Roma de Metastasio y sus traductores al español con especial atención al jesuita Benito Antonio de Céspedes». Cuadernos de Investigación Filológica, 2013, 39, pp. 187-204.

McClelland, Ivy L. Ignacio de Luzán. Nueva York: Twayne Publishers, 1973.

Meregalli, Franco. "Goldoni e Ramón de la Cruz". En Branca,Vittore y Mangini, Nicola (eds.). Studi goldoniani. Venecia: Istituto per la Collaborazione Culturale, 1960, II, pp. 795-800.

Meregalli, Franco. Presenza della letteratura spagnola in Italia. Florencia: Sansoni, 1974.

MuÑIz MuÑIZ, M. ${ }^{a}$ Nieves (coord.). Proyecto Boscán. Catálogo histórico-crítico de las traducciones de obras literarias italianas al castellano y al catalán de 1300 hasta 1939. Barcelona: Universitat de Barcelona, 2002. Web: www.ub.edu/boscan/

Napoli Signorelli, Pietro. Storia crítica dé teatri antichi e moderni. 10 vols. 1. ${ }^{a}$ ed. 1777. Nápoles: Orsino, 1813.

NAVARRO LÁzARO, Andrés. «Las traducciones castellanas de las óperas bufas de Carlo Goldoni: el caso de La Buona Figliuola». Res Diachronicae Virtual, 2004, 3, pp. 175-181.

PagÁn, Víctor. «Carlo Goldoni. Segunda parte: El drama jocoso». En Lafarga, Francisco (ed.). El teatro europeo en la España del siglo XVIII. Lleida: Universitat de Lleida, 1997a, pp. 183-194.

PagÁn, Víctor. El teatro de Goldoni en España. Comedias y dramas con música entre los siglos dieciocho y veinte. Tesis doctoral. Madrid: Universidad Complutense de Madrid, 1997b. www.tdx.cat.

Pagán, Victor. "Carlo Goldoni». En Lafarga, Francisco y Pegeneaute, Luis (eds.). Diccionario histórico de la traducción en España. Madrid: Ambos Mundos, 2004, pp. 472-475. phte.up.edu/dthe/italiano/goldoni-carlo

Palacios, Emilio. «El teatro en el siglo XVIII (hasta 1808)». En Díez Borque, José M. a y SURTZ, Ronald (eds.). Historia del teatro en España: siglo XVIII-siglo XIX. Madrid: Taurus, 1988, II, pp. 57-376.

PARDUCCI, Amos. «Traduzioni e riduzioni spagnole di drammi italiani». Giornale Storico della Letteratura Italiana, 1941, 117, pp. 98-124.

Pavis, Patrice. Diccionario del teatro. Dramaturgia, estética, semiología. Barcelona: Paidós, 1983.

Profeti, Maria Grazia. «Metastasio in Spagna all'inizio del secolo XVIII». En Commedie, riscritture, libretti: la Spagna e l'Europa. Florencia: Alinea, 2009, pp. 229-273.

QUINZIANO, Franco. España e Italia en el siglo XVIII: presencias, influjos y recepciones. Estudios de Literatura Comparada. Barañáin: EUNSA, 2008.

QuinZIANO, Franco. «Senderos de ida y vuelta. España e Italia en el Siglo de las Luces (17001759): itinerarios, presencias y recepciones culturales». The Korean Journal of Hispanic Studies, 2009, 2, pp. 169-228. www.cervantesvirtual.com/nd/ark:/59851/bmc350c0

QuinZIANO, Franco. "La traducción de las letras italianas en el siglo XVIII». En LAFARGA, Francisco y Pegeneaute, Luis (eds.). Historia de la traducción en España. Siglo XVIII. 
FIDELIDAD, LIBRE ADAPTACIÓN, RECREACIÓN. ITINERARIOS DEL TEATRO ITALIANO EN LA ESPAÑA...

Barcelona: Universitat Pompeu Fabra, 2021. http://phte.upf.edu/hte/siglo-xviii/ quinziano/

RodríGuez Alonso, Manuel. De la ilustración al romanticismo: Teatro y espectáculo italianos en España a caballo entre los siglos XVIII y XIX en las figuras de Pietro Metastasio y Vittorio Alfieri. Tesis doctoral. Granada: Universidad de Granada, 2016. http://hdl. handle.net/10481/40314

Rodríguez Gómez, Inés. Las obras de Carlo Goldoni en Espanya (1750-1800). Tesis doctoral. Valencia: Universitat de València, 1997. http://roderic.uv.es/handle/10550/38828 RODRíGuEz GómEZ, Inés. «Reforma teatral e influencia del teatro de Goldoni en las obras de Moratín». En Romera Pintor, Irene; Bruni, Arnaldo y Battistini, Andrea (eds.). Filologia e critica nella modernità letteraria. Studi in onore di Renzo Cremante. Bolonia: CLUEB, 2012, pp. 117-134.

Rogers, Paul. Goldoni in Spain. Oberlin (Ohio): The Academy Press, 1941.

Ruiz Casanova, José. Aproximación a una bistoria de la traducción en España. Madrid: Cátedra, 2000.

SuERo RocA, M. ${ }^{a}$ Teresa. El teatre representat a Barcelona de 1800 a 1830. 3 vols. Barcelona: Institut del Teatre, 1987-89. 